\title{
Disyuntivas macroeconómicas y vulnerabilidades externas del desarrollo humano en Nicaragua
}

\author{
Marco V. Sánchez Cantillo
}

RESUMEN

Nicaragua avanza hacia el logro de los Objetivos de Desarrollo del Milenio (ODM), pero no podrá alcanzar algunas de las metas en 2015. El análisis de equilibrio general contenido en este documento demuestra que es inviable que el gobierno aumente el gasto para alcanzar esas metas antes de la fecha límite de 2015. Todo incremento del gasto y la financiación públicos tendría que concentrarse en las fases iniciales, lo que entrañaría disyuntivas macroeconómicas perniciosas. Un escenario más realista consiste en retrasar el logro de los objetivos hasta el año 2020. En ese caso, la asignación del gasto público estimularía el crecimiento económico sin ocasionar dificultades macroeconómicas, aunque de todos modos el país seguiría siendo altamente vulnerable ante las conmociones externas. del Desarrollo del Departamento de Asuntos Económicos y Sociales de las Naciones Unidas. sanchezcantillo@un.org 


\section{I}

\section{Introducción}

Pese a los cambios estructurales experimentados por su economía en los dos últimos decenios, Nicaragua aún no alcanza el nivel de desarrollo económico y humano experimentado por la mayoría de los países de América Latina y el Caribe. Esto puede atribuirse en gran medida a los efectos duraderos del conflicto armado en los años ochenta y la consiguiente decisión de los Estados Unidos de América y las instituciones financieras internacionales de romper las relaciones económicas y financieras con el país (Sánchez y Vos, 2006). La situación de la deuda externa de Nicaragua era insostenible a fines de esa década y llegó a representar el $940 \%$ del producto interno bruto (PIB) en 1989. Tanto el proceso de paz como la reanudación de las relaciones económicas y financieras con los Estados Unidos de América y dichas instituciones financieras permitieron que Nicaragua cambiara de rumbo a principios de los años noventa.

La cuantiosa ayuda en forma de donaciones extranjeras allanó el camino para que el gobierno pusiera en marcha un programa de estabilización económica consistente en políticas monetarias restrictivas y una rigurosa disciplina fiscal. A los primeros indicios de estabilidad económica les siguieron las reformas fiscal y estatal, la liberalización gradual del comercio, los regímenes cambiario y financiero, y la eliminación gradual de los controles sobre la inversión extranjera directa (IED). Durante la década de 1990 las finanzas públicas

$\square$ Este documento es uno de los resultados del proyecto "Fortalecimiento de la coherencia entre las políticas macroeconómicas y sociales mediante un modelo macro-micro integrado", puesto en marcha por el Departamento de Asuntos Económicos y Sociales de las Naciones Unidas (DAES), en colaboración con la oficina del Programa de las Naciones Unidas para el Desarrollo (PNUD) en Nicaragua y el Ministerio de Hacienda y Crédito Público del país. El autor agradece a todos los que participaron y a las instituciones a las que están afiliados, y expresa un agradecimiento especial a Manuel A. Deshon, por su contribución en las fases iniciales, y a Janet Ramírez y Martín Cicowiez, por su importante papel en la compilación y uso de conjuntos de datos para ayudar a la calibración de los instrumentos de modelado utilizados. También agradece a todos los que formularon observaciones sobre una versión anterior del documento presentado en la Conferencia Anual de la Asociación para la Capacidad y el Desarrollo Humanos, celebrada en Managua del 9 al 13 de septiembre de 2013. Martín Cicowiez y Marcelo Lafleur aportaron también valiosas observaciones para mejorar el documento. Las opiniones aquí expresadas son del autor y no reflejan necesariamente las de las Naciones Unidas ni de las contrapartes en la ejecución del proyecto de desarrollo de la capacidad del DAES. estaban más saneadas y mejor controladas, se había puesto freno a la inflación y el comercio internacional cobraba impulso. Aunque la deuda externa seguía siendo muy elevada, hacia 1999 se había reducido a un 175\% del PIB.

A finales del decenio de 1990 y principios de la década de 2000, el Gobierno de Nicaragua, con la ayuda de las instituciones financieras internacionales, puso en marcha varios programas y estrategias con miras a reducir los niveles de pobreza persistentemente elevados del país. En el año 2000, Nicaragua hizo suya la Declaración del Milenio de las Naciones Unidas y se comprometió a lograr los Objetivos de Desarrollo del Milenio (ODM). El gobierno adoptó diversas metas vinculadas a los indicadores de desarrollo humano y la reducción de la pobreza extrema que se deberían alcanzar en 2015, y las incorporó en las estrategias de lucha contra la pobreza (con inclusión de la Iniciativa en Favor de los Países Pobres Muy Endeudados (PPME)) y los planes de desarrollo del país. Se han logrado ciertos progresos en relación con los indicadores sociales y la reducción de la pobreza, pero persisten algunas deficiencias importantes que entorpecen el avance del país hacia el logro de los distintos oDM. Ya se han alcanzado algunas metas, como la meta nacional con respecto a la reducción de la pobreza extrema, pero hay otras pendientes. Por ejemplo, muchos niños y niñas aún no han finalizado la enseñanza primaria, el acceso a los servicios básicos de saneamiento es inquietantemente bajo y la mortalidad materna sigue siendo un reto. Los encargados de la formulación de políticas tendrán que intensificar sus esfuerzos encaminados a lograr los ODM y establecer una base sólida con miras a la promoción del desarrollo humano. Será necesario aumentar el nivel y la eficacia del gasto y la financiación públicos, pero lograrlo en la práctica también dependerá del ritmo y la sostenibilidad del crecimiento económico.

Los cambios estructurales de la década de 1990 no se tradujeron en una recuperación económica rápida y sostenida. El crecimiento económico se redujo en la segunda mitad del decenio de 2000 debido a factores internos y externos. Las remesas provenientes del exterior (fuente fundamental de ingreso para gran parte de la población pobre) y las corrientes de IED disminuyeron inesperadamente. Los términos de intercambio se deterioraron como resultado de los aumentos del precio del petróleo y los alimentos y las reducciones de los 
precios mundiales de los principales productos básicos de exportación (Gámez y otros, 2011; Sánchez, 2011). El lento crecimiento económico y las vulnerabilidades externas se vieron exacerbados por la crisis financiera mundial de 2008-2009, cuando el comercio internacional, la IED y las remesas volvieron a contraerse, lo que presionó sobre la balanza de pagos y provocó que el crecimiento del PIB per cápita se redujera al $-2,5 \%$ en 2009. La crisis también produjo retrocesos en diversos indicadores de desarrollo humano, con lo que el logro de los ODM se ha vuelto más difícil y costoso para Nicaragua (Sánchez y Vos, 2009).

No obstante, la economía se recuperó de la crisis financiera mundial y creció aproximadamente en un promedio del 5\% en 2011-2012. Aunque la deuda externa ha ido en constante descenso, también es cierto que la financiación de los programas sociales sigue dependiendo de los recursos extranjeros. En vista de que los donantes internacionales asignan cada vez menos ayuda a los países en desarrollo, las aspiraciones de desarrollo humano en Nicaragua dependerán del acceso a créditos externos en condiciones favorables. Con ese telón de fondo, en el presente documento se procura dar respuesta a tres interrogantes:

- ¿Podrá el gobierno aumentar el gasto público con el propósito de lograr los ODM hacia 2015 sin ocasionar dificultades macroeconómicas?

- ¿Podrá aprovechar un crecimiento económico mayor y más sostenido para movilizar recursos que le permitan financiar las necesidades de gasto público? Y en caso contrario,

- ¿ ¿cuál sería un escenario más realista para conseguir esa financiación y cuáles vulnerabilidades externas podrían impedir que el país lograra los oDM?

En este documento se actualizan las estimaciones publicadas por Sánchez y Vos (2009 y 2010) respecto del gasto público adicional que sería necesario en la perspectiva de cumplir los oDM hacia 2015 en Nicaragua. El período de análisis va más allá de 2015, a fin de valorar escenarios factibles para promover el desarrollo humano (en el marco de los ODM) sin ocasionar dificultades macroeconómicas. Se evalúa además la vulnerabilidad de esos escenarios ante las conmociones externas, dados el tamaño y la apertura de la economía nicaragüense. A ese respecto, en el presente estudio se plantean conclusiones que podrían tenerse en cuenta para la formulación de la agenda de desarrollo sostenible más allá de 2015 . El proceso coordinado por las Naciones Unidas para ayudar a definir el futuro marco de desarrollo mundial permitirá subsanar las brechas existentes asociadas a los ODM y complementar la agenda del desarrollo con nuevos objetivos de sostenibilidad. El análisis efectuado comprende la aplicación de un modelo computable de equilibrio general (CGE por sus siglas en inglés) calibrado con datos de Nicaragua para generar una serie de escenarios que se evalúan. A su vez, los resultados obtenidos mediante esta metodología se utilizan para producir microsimulaciones que permiten estimar los indicadores de pobreza económica y desigualdad en relación con esos escenarios. En lugar de pretender describir esos modelos en detalle, el análisis se concentra en interpretar los resultados de los escenarios para llegar a conclusiones que permitan formular recomendaciones de política.

Luego de esta Introducción, en la sección II se señalan aspectos destacados de los avances que ya se han logrado en el cumplimiento de varios ODM y la perspectiva para el futuro, se hace referencia a las principales dificultades que afronta Nicaragua en el logro de esos objetivos de desarrollo, y se insiste en la necesidad de un crecimiento económico sostenido para hacer frente a las conmociones externas. El marco de elaboración de los modelos se expone en la sección III. En la sección IV se describen las fuentes de datos utilizadas en el modelo integral de la economía y de microsimulaciones con el propósito de generar un escenario base, seguidas en la sección $\mathrm{V}$ por el análisis de los resultados obtenidos a partir del escenario base y de varios escenarios alternativos. Las principales conclusiones y recomendaciones de política se resumen en la sección VI. 


\section{II}

\section{Logro de los Objetivos de Desarrollo del Milenio (ODM) y tareas pendientes}

\section{Avances, deficiencias y dificultades}

En la estrategia de Nicaragua de lucha contra la pobreza se hace hincapié en el logro de los oDM. Desde mediados de la década de 2000, se han asignado recursos liberados gracias al alivio de la deuda, en tanto que las nuevas donaciones recibidas por intermedio de la Iniciativa PPME se han destinado a la estrategia de lucha contra la pobreza. En el marco de esa estrategia, el gobierno ha incrementado el gasto social, aunque no en la medida necesaria como para encaminar decididamente al país hacia el logro de los oDM, como se muestra más adelante. El gasto público social aumentó levemente del 9,1\% al 9,6\% del PIB entre 2002 y 2012 (véase el cuadro 1), pero aún se mantiene muy por debajo del promedio ponderado regional del 18,6\% del PIB estimado por la Comisión Económica para América Latina y el Caribe (CEPAL, 2013) $)^{1}$. La asignación de ese gasto por sectores

\footnotetext{
${ }^{1}$ El gasto público social en Nicaragua no habría representado mucho más del $12 \%$ del PIB si no fuese por un cambio del año de base para calcular el PIB, con lo que se corrigió una subestimación del 30\% del nivel de producción.
}

en porcentaje del PIB también es bastante estable. Medido en términos per cápita, y no como proporción del PIB, el gasto público social aumentó de 69,5 dólares en 2002 a 166,6 dólares en 2012; pero aun así se considera bajo para la región.

Los esfuerzos por acrecentar el gasto público social no han sido suficientemente audaces en Nicaragua: el país sigue viéndose afectado por profundos déficit en materia de desarrollo humano, pese a haber absorbido sumas considerables de ayuda en forma de donaciones extranjeras. El problema radica en parte en que solo una fracción del alivio de la deuda se asigna específicamente a los programas de reducción de la pobreza. En 2005, por ejemplo, solo el $53 \%$ de esos fondos se asignaron específicamente a este objetivo y el $47 \%$ restante se destinó al pago de la deuda interna de la administración central (Guimarães y Avendaño, 2011). El gobierno ha intensificado los esfuerzos encaminados a financiar el gasto público social e incluso ha utilizado los ingresos fiscales para salvaguardar dicho gasto en momentos de crisis. Sin embargo, esos esfuerzos no se reflejan en un incremento del gasto público social como proporción del PIB, porque la financiación externa de ese gasto ha ido en descenso (véase el cuadro 1).

CUADRO 1

Nicaragua: gasto público asignado específicamente a la estrategia de lucha contra la pobreza, 2002-2012

\begin{tabular}{|c|c|c|c|c|c|c|c|c|c|c|c|}
\hline & 2002 & 2003 & 2004 & 2005 & 2006 & 2007 & 2008 & 2009 & 2010 & 2011 & 2012 \\
\hline Gasto público social (en porcentajes del PIB) & 9,1 & 11,1 & 12,0 & 13,1 & 9,6 & 10,2 & 10,3 & 9,9 & 9,9 & 9,6 & 9,6 \\
\hline Educación & 2,6 & 2,9 & 2,8 & 3,1 & 2,4 & 2,6 & 2,8 & 2,9 & 2,7 & 2,5 & 2,4 \\
\hline Salud & 2,9 & 3,2 & 2,9 & 3,2 & 2,5 & 2,8 & 2,7 & 2,7 & 2,8 & 2,6 & 2,7 \\
\hline Agua y saneamiento & 0,1 & 0,0 & 0,1 & 0,0 & 0,1 & 0,0 & 0,1 & 0,1 & 0,1 & 0,1 & 0,1 \\
\hline Otros & 3,5 & 4,9 & 6,2 & 6,7 & 4,6 & 4,8 & 4,7 & 4,1 & 4,4 & 4,3 & 4,4 \\
\hline Gasto público social per cápita (en dólares) & 69,5 & 85,4 & 99,2 & 116,9 & 117,9 & 135,7 & 150,0 & 140,7 & 145,8 & 156,6 & 166,6 \\
\hline \multicolumn{12}{|l|}{ Financiación del gasto público (en porcentajes) } \\
\hline Recursos fiscales & 54,8 & 33,2 & 28,3 & 38,7 & 52,0 & 51,7 & 49,6 & 55,2 & 57,3 & 61,9 & 65,6 \\
\hline Cooperación externa para el desarrollo & 36,5 & 45,5 & 48,4 & 42,3 & 33,3 & 32,3 & 33,5 & 28,3 & 27,3 & 22,6 & 21,2 \\
\hline Alivio de la deuda externa & 8,7 & 21,3 & 23,3 & 19,0 & 14,6 & 15,9 & 16,9 & 16,5 & 15,5 & 15,5 & 13,3 \\
\hline
\end{tabular}

Fuente: informes presupuestarios del Ministerio de Hacienda y Crédito Público.

Nota: algunas cifras de los informes presupuestarios se convirtieron a la moneda nacional utilizando el tipo de cambio medio del Banco Central de Nicaragua (BCN). La reducción del gasto público social en porcentaje del PIB de 2005 a 2006 se explica por un cambio en el año de base para calcular el PIB de 1994 a 2006, con lo que se corrigió una subestimación del 30\% del nivel del pIB. Los recursos fiscales incluyen los ingresos tributarios y los ingresos asignados a un fin específico. La cooperación externa para el desarrollo comprende donaciones y préstamos. El alivio de la deuda externa incluye el alivio de la deuda en el marco de la Iniciativa ppme y la cancelación de la deuda con el Club de París.

PIB: producto interno bruto. 
Los programas y estrategias encaminados a la reducción de la pobreza y el logro de los objetivos en materia de desarrollo humano han acelerado los avances en la consecución de los ODM, pero no se ha logrado que todos esos objetivos se hallen cercanos a su cumplimiento en 2015 (véase el cuadro 2). El nivel de pobreza a nivel nacional ha disminuido por varias razones, en particular, debido al mejoramiento de las condiciones de vida en las zonas rurales. Esa mejora se puede atribuir en parte a la eficacia de los programas que promueven la producción de alimentos básicos, la reducción de los precios al consumidor de esos productos $\mathrm{y}$, en términos más generales, las entradas de remesas. Ya se ha alcanzado la meta nacional en materia de pobreza extrema (16,3\%); sin embargo, la meta internacional $(9,7 \%)$ de disminuir a la mitad la pobreza extrema en comparación con su nivel de 1993 sigue siendo una aspiración difícil de hacer realidad. La volatilidad del crecimiento económico ha obstaculizado el logro de mayores reducciones de la pobreza extrema. Medida como porcentaje de la población que vive con menos de un dólar al día, la pobreza extrema aumentó levemente entre 1998 y 2001 con la desaceleración de la economía. En esos años, una fracción del gasto público social se reasignó a las medidas de recuperación en casos de desastres naturales. La población que vive en la pobreza moderada y extrema volvió a crecer en
2005 durante otra recesión económica. Los programas de reducción de la pobreza contribuyeron a revertir la situación: las pobrezas moderada y extrema disminuyeron en 2009, aunque los datos disponibles que provienen de las encuestas más recientes -durante la elaboración de este documento - no reflejan todo el impacto de la crisis financiera mundial en la pobreza.

Los resultados de la enseñanza primaria han sido generalmente satisfactorios. Se ha incrementado la matrícula neta, pero deberá aumentar 11 puntos porcentuales más para que el país cumpla una de las metas clave del segundo oDM. Con todo, la dificultad principal en la educación no es la matrícula neta, sino el hecho de que menos del $50 \%$ de los estudiantes que se matriculan en primaria llegan a finalizar el ciclo. Con el gasto público en educación se ha mejorado la infraestructura en el sector y se ha prestado asistencia a los estudiantes pobres mediante programas de almuerzos escolares y transferencias monetarias condicionadas. También se ha procurado elevar la calidad de la enseñanza por medio de la modernización del sector. No obstante, a pesar de esos esfuerzos, hasta la fecha el gasto ha sido insuficiente o ineficaz, o ambas cosas, pues siguen siendo altos los índices de repetición y deserción escolar. El sector público tropieza con enormes limitaciones de capacidad de la infraestructura en lo que se refiere a escuelas y materiales de enseñanza. No hay un número suficiente

CUADRO 2

Nicaragua: indicadores de los Objetivos de Desarrollo del Milenio (ODM) y de pobreza (1990-2011) y meta para 2015

\begin{tabular}{|c|c|c|c|c|c|}
\hline Indicador & 1990 & 2000 & 2005 & 2011 & Meta para 2015 \\
\hline Pobreza moderada nacional (en porcentajes) & $\begin{array}{c}50,3 \\
(1991)\end{array}$ & $\begin{array}{c}45,8 \\
(2001)\end{array}$ & 48,3 & $\begin{array}{c}42,5 \\
(2009)\end{array}$ & \\
\hline Primer ODM: pobreza extrema nacional (en porcentajes) & $\begin{array}{c}19,4 \\
(1991)\end{array}$ & $\begin{array}{c}15,1 \\
(2001)\end{array}$ & 17,2 & $\begin{array}{c}14,6 \\
(2009)\end{array}$ & 9,7 \\
\hline $\begin{array}{l}\text { Segundo oDM: índice neto de matriculación en enseñanza primaria } \\
\text { (en porcentajes) }\end{array}$ & $\begin{array}{c}72,6 \\
(1991)\end{array}$ & 80,5 & 87,1 & 88,9 & 100,0 \\
\hline $\begin{array}{l}\text { Segundo oDM: porcentaje de estudiantes que comienzan y finalizan } \\
\text { la enseñanza primaria (en porcentajes) }\end{array}$ & $\cdots$ & 35,4 & $\begin{array}{c}43,0 \\
(2006)\end{array}$ & $\begin{array}{c}41,5 \\
(2010)\end{array}$ & \\
\hline $\begin{array}{l}\text { Cuarto oDM: mortalidad de menores de cinco años } \\
\text { (muertes por cada } 1000 \text { nacidos vivos) }\end{array}$ & 72,0 & $\begin{array}{c}37,0 \\
(2001)\end{array}$ & $\begin{array}{l}35,0 \\
(2006)\end{array}$ & 25,0 & 17,0 \\
\hline $\begin{array}{l}\text { Quinto oDM: mortalidad materna } \\
\text { (muertes por cada } 1000 \text { nacidos vivos) }\end{array}$ & 160,0 & 87,0 & 86,5 & 62,0 & 40,0 \\
\hline $\begin{array}{l}\text { Séptimo oDM: porcentaje de la población con acceso a mejores servicios } \\
\text { de agua potable (en porcentajes) }\end{array}$ & 57,7 & $\begin{array}{c}78,6 \\
(2002)\end{array}$ & 90,5 & $\cdots$ & 85,0 \\
\hline $\begin{array}{l}\text { Séptimo oDM: porcentaje de la población con acceso a mejores servicios } \\
\text { de saneamiento (en porcentajes) }\end{array}$ & $\cdots$ & $\begin{array}{c}27,9 \\
(2002)\end{array}$ & 37,2 & $\begin{array}{c}39,8 \\
(2008)\end{array}$ & 72,5 \\
\hline
\end{tabular}

Fuente: datos de pobreza del Instituto Nacional de Información de Desarrollo (INIDE); datos de educación del Ministerio de Educación (MINED); datos de mortalidad del Ministerio de Salud (MINSA) y la Organización Panamericana de la Salud (OPS), excepto los de 2011; datos de mortalidad correspondientes a 2011 del Plan Nacional de Desarrollo Humano 2012-2016, y datos sobre el agua y el saneamiento de la Empresa Nicaragüense de Acueductos y Alcantarillados (ENACAL).

Nota: las tasas de pobreza representan el porcentaje de la población cuyo consumo per cápita es inferior a las respectivas líneas de pobreza oficiales. 
de maestros calificados y su remuneración es baja. Fue hace poco que se orientó a todas las escuelas primarias de zonas rurales para que impartieran enseñanza a todos los grados del ciclo. Las malas condiciones en materia de bienestar, la migración y el costo de la enseñanza limitan acentuadamente la demanda de educación, pues un gran número de niñas y niños abandonan la escuela o no llegan a matricularse, sobre todo en zonas rurales, donde la pobreza es mayor y el trabajo infantil sigue siendo una realidad preocupante.

La mortalidad de los niños menores de cinco años ha disminuido sistemáticamente gracias a políticas sociales que han promovido la mejora y ampliación de los servicios de salud, a fin de reducir la vulnerabilidad nutricional y educativa de los niños. Esa tendencia se ha visto fortalecida merced a las campañas de vacunación y lactancia materna que se han ampliado a sectores más amplios de la población, al aumento del uso de la rehidratación oral y de las terapias de control de infecciones, a las nuevas inversiones públicas en servicios básicos en zonas rurales y a los sistemas integrados de protección social de niños menores de seis años que viven en condiciones de extrema pobreza. Empero, alcanzar la meta de 17 decesos por cada 1.000 nacidos vivos sigue siendo un reto y con ese fin será necesario asignar específicamente una proporción mayor del gasto público en salud a objeto de reducir aún más la prevalencia de las enfermedades diarreicas, las infecciones respiratorias agudas, los nacimientos prematuros y los problemas vinculados al bajo peso al nacer, la asfixia y la septicemia.

Las perspectivas son menos alentadoras respecto de la mortalidad materna, aunque el número de decesos por cada 100.000 nacidos vivos se redujo de 160 en 1990 a 62 en $2011^{2}$. Las complicaciones durante el parto siguen siendo una de las principales causas de muerte de las mujeres en edad reproductiva. A objeto de alcanzar la meta de reducir la mortalidad materna a 40 muertes por cada 100.000 nacidos vivos hacia 2015 , será necesario un crecimiento mayor y más sostenido del gasto en salud pública. Las esferas prioritarias se orientan al aumento de la calidad y el acceso a la atención prenatal y postnatal, la asistencia durante el parto y la prevención de complicaciones en el embarazo. Se deben hacer mejoras en la eficiencia de los servicios de salud, el incremento del acceso y la capacidad de

\footnotetext{
${ }^{2}$ Las cifras de mortalidad materna en Nicaragua varían significativamente según su proveniencia.
}

la infraestructura hospitalaria, especialmente en los niveles de atención primaria y secundaria, la ampliación del cuidado preventivo y la promoción de la salud en hogares y comunidades, sobre todo en las zonas rurales.

Por último, aunque no por ello menos importante, Nicaragua también se comprometió a reducir a la mitad la proporción de la población que no tiene acceso al agua potable y a mejorar los servicios de saneamiento entre 1990 y 2015. Ya se ha alcanzado la meta relativa al agua potable, sobre todo gracias a los programas de inversión de la Empresa Nicaragüense de Acueductos y Alcantarillados (ENACAL), con los que se ha ampliado el acceso al agua potable en zonas rurales y en vecindarios de Managua. Los programas de alcantarillado de la ENACAL y los proyectos de letrinas rurales del Fondo de Inversión Social de Emergencia (FISE) han beneficiado a miles de hogares en años recientes. Pese a ello, solo el $40 \%$ de la población tenía acceso a mejores servicios de saneamiento en 2011. El país tendrá dificultad para alcanzar su meta de aumentar el acceso al 72,5\% de la población en 2015, a menos que haya un incremento más sostenido del gasto público con miras a ampliar y mejorar la infraestructura de alcantarillado y letrinas rurales.

Las deficiencias existentes en materia de enseñanza primaria, mortalidad materna y saneamiento básico solo se eliminarán si se acrecienta el gasto público social, de modo que se puedan aplicar políticas eficaces en función de los costos. Sánchez y Vos (2009 y 2010) concluyeron que el crecimiento económico continuo y la aplicación de las políticas de gasto público vigentes antes de la crisis financiera mundial contribuirían a lograr notables progresos en diversos indicadores, pero no serían suficientes para alcanzar todas las metas en 2015. Los autores estiman que, antes de la crisis financiera mundial, el gasto público social adicional necesario para alcanzar esas metas en Nicaragua oscilaba entre el 3,6\% y el 4,7\% del PIB cada año durante el período 2000-2015, según cuál fuera la fuente de financiación. Esas estimaciones se revisaron al alza en 1,7 puntos porcentuales del PIB después de tomar en consideración los efectos de la crisis financiera mundial en el gasto social privado y los $\mathrm{ODM}^{3}$.

\footnotetext{
${ }^{3}$ Más adelante se presenta una actualización de esas estimaciones, pero con dos precisiones mayores respecto del análisis de los escenarios. En primer lugar, dado que ya ha comenzado el año 2015, se amplió el período de simulación a fin de evaluar las estrategias de financiación factibles respecto del gasto necesario para lograr los ODM. En segundo lugar, el análisis esclarece algunos aspectos de la vulnerabilidad ante las conmociones externas de un escenario factible respecto del logro de los ODM.
} 


\section{Crecimiento económico y vulnerabilidad externa}

El crecimiento económico sostenido es muy necesario en Nicaragua para eliminar las disparidades de desarrollo antes descritas. Se debería hacer hincapié en mejorar los ingresos y estimular la demanda privada de servicios sociales, lo que permitiría al gobierno obtener mayores ingresos tributarios e incrementar así el gasto público social y las inversiones en infraestructura. Como ya se indicó, el Gobierno de Nicaragua ha intensificado los esfuerzos con el propósito de financiar el gasto público social e incluso ha utilizado los ingresos fiscales como forma de salvaguardar dichos gastos durante períodos de crisis. Esto resulta particularmente importante en un momento en que han ido disminuyendo el acceso a préstamos en condiciones favorables y la ayuda en forma de donaciones; de hecho, esta última representó apenas un 2,6\% del PIB cada año en el período 20102012 (véase el cuadro 3).

Los ingresos tributarios han ido en constante aumento gracias a las diversas reformas fiscales promulgadas desde mediados de los años noventa: estas representaron el 20,8\% del PIB cada año en el período 2010-2012, es decir, 8 puntos porcentuales más que en la segunda mitad de la década de 1990 (véase el cuadro 3). La reforma fiscal más reciente consistió en la aprobación de la Ley de Concertación Tributaria (Ley N ${ }^{\circ}$ 822) en 2012. Sin embargo, no se espera que las nuevas reformas destinadas a ampliar la base impositiva y engrosar los ingresos produzcan un incremento sustancial de estos. Debido al éxito de las reformas fiscales anteriores, más bien se han reducido las posibilidades de generar ingresos tributarios aun mayores en un período relativamente corto. Las políticas de gasto público seguirán dependiendo en gran medida de los recursos extranjeros, aunque también existe la remota posibilidad de que los mercados financieros nacionales poco activos consigan movilizar algunos recursos internos.

El frágil acceso a préstamos en condiciones favorables y a la ayuda, las preocupaciones sobre la sostenibilidad de la deuda y la falta de margen de acción para seguir aumentando los ingresos tributarios a corto plazo socavan la capacidad del país de movilizar recursos en apoyo a los objetivos en materia de desarrollo humano. Por lo tanto, el crecimiento económico sostenido es decisivo si se desea crear un mayor espacio para la movilización de los recursos internos en apoyo a dicho desarrollo. Lamentablemente, los logros económicos resultantes de las medidas de estabilización y las

CUADRO 3

Nicaragua: indicadores macroeconómicos, 1990-2012

(En promedios anuales)

\begin{tabular}{|c|c|c|c|c|c|}
\hline Indicador & $1990-1994$ & 1995-1999 & $2000-2004$ & $2005-2009$ & 2010-2012 \\
\hline \multicolumn{6}{|c|}{$\begin{array}{l}\text { Finanzas públicas, asistencia oficial para el desarrollo (AOD) } \\
\text { y deuda pública externa (en porcentajes del PIB) }\end{array}$} \\
\hline Ingreso tributario & 20,5 & 12,9 & 15,3 & 18,7 & 20,8 \\
\hline Balanza fiscal, antes de las donaciones & $-10,2$ & $-5,7$ & $-6,9$ & $-3,3$ & $-1,8$ \\
\hline Balanza fiscal, después de donaciones & $-3,7$ & $-1,4$ & $-3,3$ & $-0,3$ & $-0,2$ \\
\hline Endeudamiento externo & 7,6 & 3,9 & 4,3 & 2,8 & 2,1 \\
\hline Endeudamiento interno & $-4,0$ & $-2,5$ & $-2,2$ & $-2,6$ & $-1,9$ \\
\hline AOD & 41,4 & 17,1 & 13,7 & 9,0 & 5,4 \\
\hline Préstamos en condiciones favorables & 18,9 & 8,9 & 6,5 & 4,0 & 2,8 \\
\hline o préstamos concesionarios & & 8,2 & 7,2 & 5,0 & 2,6 \\
\hline Donaciones & 22,6 & & & & \\
\hline Deuda pública externa & 593,9 & 206,6 & 152,8 & 61,9 & 42,7 \\
\hline \multicolumn{6}{|l|}{ Sector externo (en porcentajes del PIB) } \\
\hline Balanza por cuenta corriente & $-46,2$ & $-23,4$ & $-18,7$ & $-14,5$ & $-12,0$ \\
\hline Inversión extranjera directa (IED) & 1,7 & 4,8 & 5,2 & 5,4 & 7,9 \\
\hline Remesas & 1,1 & 4,7 & 9,6 & 10,4 & 9,6 \\
\hline \multicolumn{6}{|l|}{ Producción (tasa de crecimiento) } \\
\hline PIB real & 0,6 & 5,4 & 3,1 & 3,1 & 4,8 \\
\hline PIB real per cápita & 13,3 & 2,7 & 2,2 & 5,8 & 6,8 \\
\hline
\end{tabular}

Fuente: Banco Central de Nicaragua (BCN).

Nota: la balanza fiscal y su financiación se refieren al sector público no financiero. La concesión neta de préstamos se consideraba parte de la balanza fiscal hasta el año 2000, y desde entonces pasó a ser parte del endeudamiento interno. En la categoría de donaciones se incluyen algunas donaciones extranjeras líquidas vinculadas a proyectos y alivio provisional de la deuda de la Iniciativa PPME.

PIB: producto interno bruto. 
reformas económicas, así como algunos episodios de condiciones externas favorables, no se han traducido en la recuperación económica rápida y sostenida que Nicaragua necesita a largo plazo (véase el gráfico 1). El crecimiento del PIB per cápita era inestable en la década de 1990, cuando promedió un 2,7\% anual, y posteriormente disminuyó al 2,2\% anual en el período 2000-2004 (véase el cuadro 3). No obstante, luego mejoraron las perspectivas cuando el PIB per cápita aumentó un 5,8\% durante el período 2005-2009 y un 6,8\% en el período 2010-2012.

En diversos estudios se indica que la estabilidad del crecimiento económico en Nicaragua se ha visto afectada negativamente por las condiciones externas desfavorables (véanse, por ejemplo, Gámez y otros, 2011; Sánchez, 2011; Sánchez y Vos, 2006). Las vulnerabilidades externas están arraigadas en una serie de factores. Por ejemplo, las políticas de promoción de las exportaciones y las minidevaluaciones del tipo de cambio han contribuido a que los productos de exportación sean más competitivos, pero su falta de diversificación sigue siendo una preocupación importante, sobre todo porque las exportaciones se encuentran entre los factores que más contribuyen al crecimiento económico en Nicaragua. Los textiles (incluidos los productos de cuero), la carne y el café representaban, respectivamente, el $16 \%$, el $17 \%$ y el 9\% de las exportaciones totales en 2011. En conjunto, esos tres grupos de productos representan casi la mitad de las exportaciones totales. Afortunadamente para
Nicaragua, el valor de sus principales exportaciones no se ha visto tan afectado por los precios mundiales, que en general se mantuvieron favorables entre 1994 y 2011. Año a año, los precios de las exportaciones muestran solo una caída de los precios de los textiles (8\% en 2009) y cuatro reducciones de los precios del café (cada una de alrededor del 20\% en 1996, 1999, 2000 y 2001) (véase el gráfico 2). Los precios del café cayeron un 23\% en 2013 (ese dato no se indica en el gráfico 2). Los precios mundiales siguen siendo una posible fuente de vulnerabilidad externa debido a la falta de diversificación de las exportaciones.

El valor de las importaciones totales ha aumentado con mayor rapidez que el de las exportaciones totales, debido sobre todo a las facturas cada vez más elevadas de las importaciones de petróleo refinado. Este rubro representó el 11\% de las importaciones totales en 2011 y su precio ha aumentado en un $21 \%$ anual desde 1994 (véase el gráfico 2). El consiguiente déficit comercial se ha visto contrarrestado por las remesas provenientes del exterior y la IED, que han contribuido a aminorar el déficit en cuenta corriente de la balanza de pagos (véase el cuadro 3). La IED ha seguido una marcada tendencia ascendente desde el segundo quinquenio de la década de 1990, se estabilizó en alrededor del 5\% del PIB anual en el decenio de 2000 y luego se abultó a casi el 8\% del PIB en 2010-2012 (véase el cuadro 3). En el período 1990-2012, las entradas de IED en Nicaragua se redujeron en 10 ocasiones, y en 5 de ellas

GRÁFICO 1

Nicaragua: PIB y crecimiento del PIB per cápita en términos reales, 1991-2012 (En porcentajes)

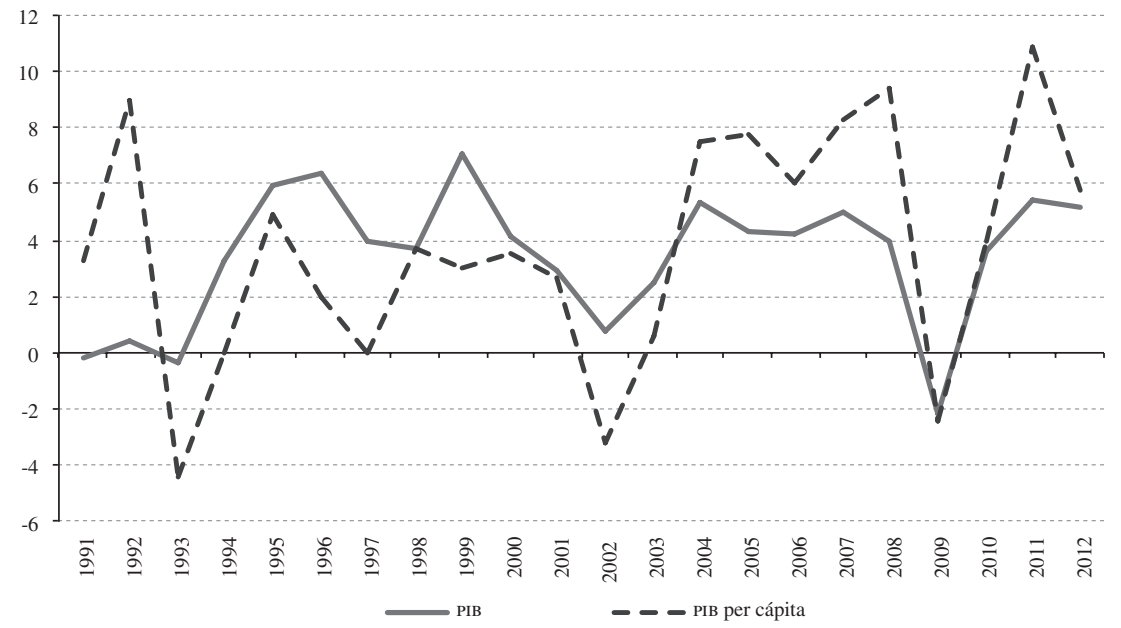

Fuente: Banco Central de Nicaragua (BCN).

PIB: producto interno bruto. 
experimentaron una caída sustancial de más de 1 punto porcentual del PIB (véase el gráfico 3). Las entradas de remesas han sido relativamente más estables que la IED, aunque también se redujeron en siete ocasiones entre 1990 y 2012, siendo las más destacadas la de 1,4 puntos porcentuales del PIB en 2006 y la de 0,5 puntos del PIB en 2009. La balanza de pagos, un factor decisivo para lograr un crecimiento económico sostenido, es altamente vulnerable al debilitamiento de las entradas de remesas e IED. Esas vulnerabilidades externas podrían poner en peligro los esfuerzos del país en pos del logro de los objetivos en materia de desarrollo humano.

GRÁFICO 2

Nicaragua: índice implícito de los precios de los principales productos básicos de exportación e importación, 1994-2011 $(1994=100)$

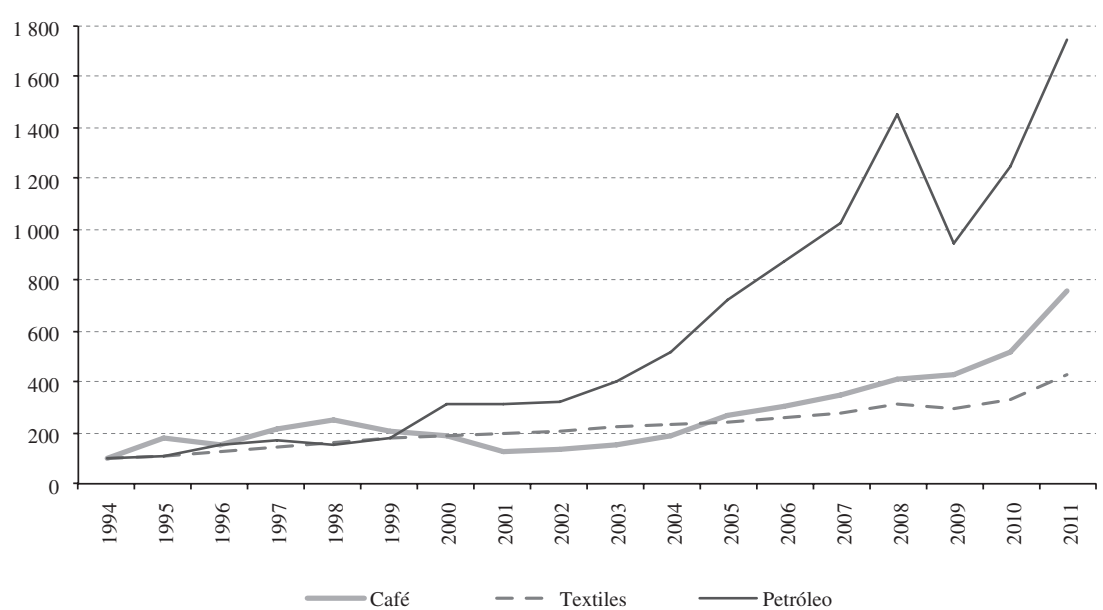

Fuente: Banco Central de Nicaragua (BCN).

GRÁFICO 3

Nicaragua: entradas netas de inversión extranjera directa (IED) y remesas, 1990-2012

(En porcentajes del PIB)

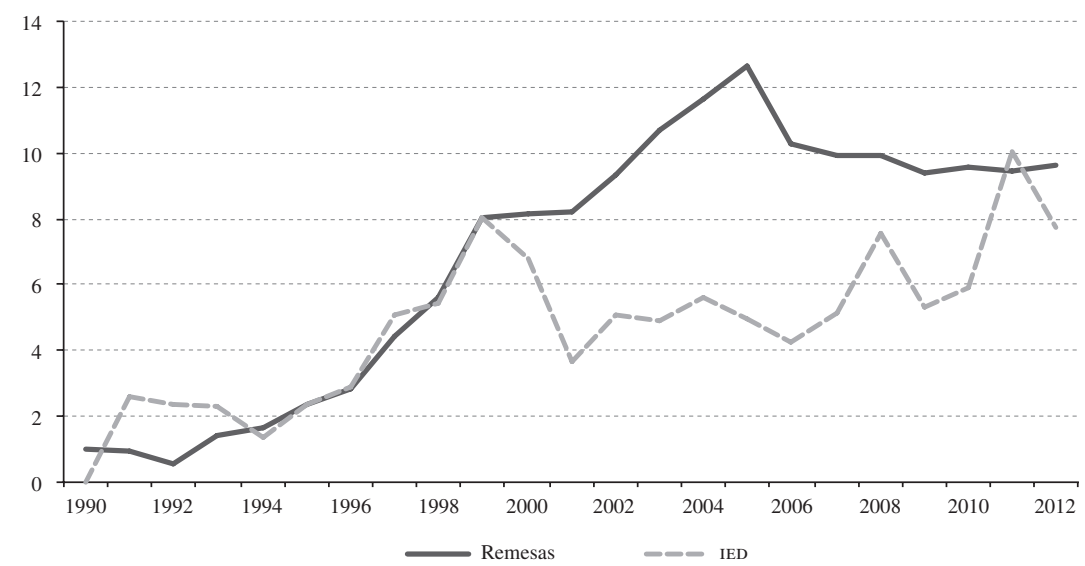

Fuente: Banco Central de Nicaragua (BCN).

PIB: producto interno bruto. 


\section{III}

\section{Marco de elaboración de modelos}

Se necesita un marco de elaboración de modelos de toda la economía para el análisis de los escenarios que se realizó con el propósito de cuantificar el gasto público social y la financiación adicionales requeridos para alcanzar las metas de los ODM. En este artículo se utiliza el Modelo de Simulación sobre los Objetivos de Desarrollo del Milenio (conocido como MAMs por sus siglas en inglés). Este modelo cGE dinámico-recursivo es un sistema de ecuaciones simultáneas y no lineales; alcanza un equilibrio a partir de ecuaciones que definen, entre otros elementos, el comportamiento (de consumidores, productores y otros), el equilibrio macroeconómico (cuentas fiscales, balanza de pagos, balanzas de ahorro e inversión, entre otros) y el equilibrio del mercado (de bienes y servicios, factores y otros). El modelo MAMs se describe con detalle en Lofgren y Díaz-Bonilla (2010) y en Lofgren, Cicowiez y Díaz-Bonilla (2013). Como se explica en esos documentos, el modelo es innovador porque incluye un conjunto de objetivos básicos de desarrollo humano en su módulo relativo a los ODM y la enseñanza; sobre el modelo se ofrecen a continuación mayores pormenores. En este trabajo se va más allá al aplicar el modelo MAMS para abordar las vulnerabilidades externas del logro de los ODM en Nicaragua.

La utilización de un modelo CGE dinámicorecursivo, en este caso el modelo MAMs, se justifica porque las estrategias aplicadas en la perspectiva de lograr los ODM es probable que surtan un gran efecto en toda la economía. Tales estrategias pueden influir en la demanda y la oferta en los distintos mercados (de bienes y servicios, factores productivos y tipos de cambio de divisas) y los correspondientes ajustes podrían entrañar importantes disyuntivas durante todo el período previsto para el logro de los oDM e incluso más allá. En el modelo MAMS se toman en consideración específicamente las posibles sinergias existentes entre los distintos ODM en su módulo sobre los oDM y la enseñanza. Esas sinergias podrían influir en la necesaria expansión de los servicios (por ejemplo, un mayor acceso al agua potable podría no hacer tan necesario ampliar los servicios de salud) o en la rapidez con que se cumplen los distintos ODM.

La estrategia adoptada para financiar el gasto público que se necesita para lograr esos ODM también influye en los resultados. Por ejemplo, la financiación externa podría influir en el tipo de cambio real, en tanto que la financiación con ingresos tributarios internos podría reducir la demanda del consumo privado y el endeudamiento interno podría desplazar los recursos crediticios que se habrían destinado a la inversión privada. Sin duda, el aumento del gasto público es esencial para lograr los objetivos en materia de desarrollo humano, pero los ajustes del tipo de cambio real, los salarios reales y otros precios relativos podrían acarrear el incremento de los costos unitarios para lograr esos objetivos —además de los costos relacionados con otros sectores-, como también desincentivar las exportaciones, con lo que se ampliaría el déficit externo que es preciso financiar, entre otras consecuencias. Los aumentos de productividad obtenidos exclusivamente al alcanzar mayores niveles de desarrollo humano tomarán un tiempo para materializarse $\mathrm{y}$, por lo tanto, no es probable que tengan un efecto inmediato en el crecimiento económico. El modelo MAMS constituye una herramienta útil para evaluar las disyuntivas macroeconómicas de la financiación del desarrollo por medio del gasto público, a fin de determinar si los posibles beneficios económicos y sociales que se cosecharán a largo plazo servirían de contrapeso a esas disyuntivas.

En el módulo sobre los oDM y la enseñanza se especifican los determinantes principales de su logro que no se vinculan directamente con la pobreza económica (es decir, los objetivos no relacionados con la pobreza) y el impacto directo de un mayor gasto público en la infraestructura y los servicios relacionados con los ODM (véase el cuadro 4). Se toman en consideración metas específicas para lograr los objetivos no relacionados con la pobreza, como son el acceso a la enseñanza primaria universal (segundo ODM), la reducción de la mortalidad de los niños menores de cinco años y la mortalidad materna (cuarto y quinto oDM) y el aumento del acceso al agua potable y al saneamiento básico (séptimo ODM). El indicador utilizado en el segundo oDM no es la matrícula, sino el índice neto de finalización a tiempo de la enseñanza primaria, que es una función del comportamiento estudiantil (matrícula, promoción, graduación), puesto que la mayoría de los países en desarrollo ya han alcanzado niveles aceptables de matriculación en la enseñanza primaria. Se establece una meta relativa a la finalización a tiempo de la enseñanza primaria, sin repetición y aplicable a la cohorte de edad correspondiente. A su vez, el comportamiento estudiantil depende de la calidad de la enseñanza (prestación de 
Determinantes de los Objetivos de Desarrollo del Milenio (ODM) no relacionados con la pobreza

\begin{tabular}{|c|c|c|c|c|c|}
\hline Objetivo de Desarrollo del Milenio & $\begin{array}{l}\text { Prestación de } \\
\text { servicios }\end{array}$ & $\begin{array}{l}\text { Consumo per cápita } \\
\text { de los hogares }\end{array}$ & $\begin{array}{l}\text { Incentivos } \\
\text { salariales }\end{array}$ & $\begin{array}{l}\text { Infraestructura } \\
\text { pública }\end{array}$ & Otros $\mathrm{ODM}^{\mathrm{a}}$ \\
\hline \multicolumn{6}{|l|}{ 2: Enseñanza primaria } \\
\hline i) Matriculación & 1,0000 & 0,3063 & 1,3650 & 0,3815 & $-0,6300($ oDM 4) \\
\hline ii) Promoción & 1,0000 & 0,1187 & 1,5167 & 0,1715 & $-0,0035$ (ODM 4) \\
\hline \multirow[t]{2}{*}{ 4: Mortalidad de menores de cinco años } & $-0,8550$ & $-0,6133$ & & $-0,2000$ & $-0,3268($ ODM $7 \mathrm{w})$ \\
\hline & & & & & $-0,3268($ oDM $7 \mathrm{~s})$ \\
\hline \multirow[t]{2}{*}{ 5: Mortalidad materna } & $-0,9500$ & $-0,6133$ & & $-0,2000$ & $-0,1315($ ODM $7 w)$ \\
\hline & & & & & $-0,1315($ ODM $7 \mathrm{~s})$ \\
\hline 7: Acceso a agua potable & 0,3600 & 0,1120 & & 0,0020 & \\
\hline 7: Acceso a saneamiento básico & 0,8000 & 0,6625 & & 0,5880 & \\
\hline
\end{tabular}

Fuente: H. Lofgren, M. Cicowiez y C. Díaz-Bonilla, "MAMS-A computable general equilibrium model for developing country strategy analysis", Handbook of Computable General Equilibrium Modelling, P.B. Dixon and D.W. Jorgenson (eds.), vol. 1A, Amsterdam, NorthHolland, 2013, pág. 223 y estimaciones de elasticidades para Nicaragua (en paréntesis) basadas en los hallazgos del estudio de J. Pacheco, "Determinantes socioeconómicos de la educación, la mortalidad y el acceso al agua potable y el saneamiento en Nicaragua: Un análisis econométrico", 2013 [en línea] http://www.un.org/en/development/desa/policy/capacity/country_documents/nicaragua_determinantes.pdf.

a El ODM 7w se refiere a la meta sobre el acceso al agua potable y el oDM 7s se refiere a la meta relativa al saneamiento.

servicios por estudiante), el consumo per cápita de los hogares (como indicador del nivel de vida), los incentivos de los ingresos (la prima salarial que se prevé de la enseñanza), la mortalidad en la niñez (indicador indirecto de la situación sanitaria de la población estudiantil) y la infraestructura pública (carreteras, puentes, redes eléctricas y otros, que facilitan el acceso y el funcionamiento de los centros de educación). A medida que aumenta el índice de finalización en todos los ciclos de enseñanza, la composición de la fuerza de trabajo en función de los conocimientos especializados pasa a tener una mayor proporción de trabajadores calificados, con lo que se establece un vínculo directo entre el funcionamiento del sistema educativo y el mercado laboral. Por otra parte, las tasas de mortalidad de menores de cinco años y de mortalidad materna están determinadas por la disponibilidad per cápita de servicios de salud públicos y privados, el consumo per cápita de los hogares, el nivel de infraestructura pública (carreteras, puentes y redes eléctricas, que facilitan el acceso a los centros de salud y los hospitales y su funcionamiento), y el acceso a servicios de agua y saneamiento. Los determinantes del acceso al agua y el saneamiento son el consumo per cápita de los hogares, la prestación de servicios de agua y saneamiento por entidades públicas o privadas, y la infraestructura pública.

La eficacia de los determinantes de los objetivos no relacionados con la pobreza sigue un patrón no lineal. Para ello se utilizan funciones logísticas correspondientes a la "producción" de los distintos indicadores de los ODM y los comportamientos de los estudiantes, las que se generan de tal manera que la eficacia de cada determinante va disminuyendo a medida que se avanza hacia la meta.
A la hora de determinar si un país se encuentra bien encaminado al logro de sus objetivos de desarrollo, esa característica no lineal hace que el modelo mams sea una herramienta más adecuada que otros modelos con que se ha intentado determinar este parámetro mediante la proyección lineal de las tendencias del pasado. Si bien los servicios sociales pueden ser prestados por entidades públicas o privadas, solo la nueva inversión del gobierno y el gasto actual propiciarán el tipo de aumento impulsado por las políticas en la prestación de servicios sociales y de infraestructura pública que puede garantizar el logro de una o más metas de desarrollo. Se desarrollan escenarios hipotéticos en los que el gobierno moviliza suficientes recursos internos o externos como para financiar el nuevo gasto necesario para alcanzar las metas. La expresión matemática del modelo que capta esos mecanismos de transmisión se explica pormenorizadamente en Lofgren y Díaz-Bonilla (2010) y Lofgren, Cicowiez y Díaz-Bonilla (2013).

El objetivo de reducir la pobreza extrema (primer ODM) no se aborda de la misma manera que los objetivos no relacionados con la pobreza, debido a la falta de instrumentos que los encargados de la formulación de políticas pudieran utilizar de manera realista para lograr resultados específicos en la lucha contra la pobreza en la mayoría de los contextos reales de los países en desarrollo. Dado que se utilizan hogares representativos, un modelo CGE como el MAMs no suele alcanzar el nivel de detalle de la distribución de los ingresos requerido para estimar adecuadamente la pobreza a nivel de los hogares. Esa deficiencia se supera mediante el uso del modelo de microsimulaciones no paramétricas descrito y aplicado en Vos y Sánchez (2010). 
De este modo se toma en cuenta la distribución de los ingresos registrada en las encuestas de hogares, sin definir supuestos acerca de su distribución en el seno del hogar representativo utilizado en el modelo CGE. En relación con diversas variables del mercado laboral extraídas de los escenarios hipotéticos generados mediante el modelo CGE (desempleo según el tipo de ocupación, empleo y salarios por sector, nivel global de remuneración media y composición de la población empleada en función de los conocimientos especializados), los cambios correspondientes a cada año se calculan en relación con un año de base de las microsimulaciones. Dichos cambios se someten a una aproximación en ellas a nivel micro mediante un procedimiento de selección aleatoria dentro de los segmentos del mercado laboral, definidos estrictamente en función de categorías ocupacionales por nivel educativo y sectores de empleo. Se aplica un proceso de selección aleatoria a fin de determinar, en relación con cada año y entre los miembros del grupo en edad laboral, quiénes cambian su situación dentro de la fuerza de trabajo (empleo o desempleo); quiénes cambian su sector de empleo; cuáles son los empleados que mejoran su nivel de educación, y cómo se asignan las nuevas rentas del trabajo a las personas incluidas en la muestra. El supuesto fundamental es que, en promedio, esas variaciones ocupacionales ocasionadas por los cambios aleatorios reflejan adecuadamente el efecto de los cambios reales en el mercado laboral. Debido a la introducción de un proceso de asignación aleatoria, las microsimulaciones se repiten muchas veces para cada año del período de simulación, al estilo del método de Monte Carlo. En cada ocasión, los cambios del mercado laboral se superponen a una distribución determinada, derivada de una reciente encuesta de hogares, para poder generar una nueva distribución de las rentas del trabajo. A fin de realizar las microsimulaciones, se mantiene la coherencia entre el año de la encuesta de hogares y el año respecto del que se expresan todos los cambios ocupacionales extraídos del modelo CGE. Los cambios de los ingresos no laborales, así como las transferencias gubernamentales y las remesas del exterior — que, mediante valores extraídos del modelo CGE, también se computan por cada año de los escenarios hipotéticos en relación con el año de base utilizado en las microsimulaciones- se incrementan o se reducen proporcionalmente a objeto de volver a estimar la nueva distribución de los ingresos de los hogares. A su vez, dicha cifra y la propensión marginal al consumo por producto se emplean para generar una nueva distribución del consumo. Sobre la base de ese proceso, se construyen intervalos de confianza del $95 \%$ en el caso de los índices de pobreza y desigualdad estimados a partir de las nuevas distribuciones de los ingresos y del consumo.

\section{IV}

\section{Datos, calibración y escenario base}

La estructura contable básica del modelo MAMs se deriva de una matriz de contabilidad social correspondiente a 2006. En ella se integran, en un marco contable coherente, los datos de las cuentas nacionales oficiales (cuadros de oferta y utilización, cuentas de las instituciones y principales agregados macroeconómicos), las cuentas fiscales, la información sobre la balanza de pagos y una reciente encuesta de hogares. Dicha matriz posee las siguientes características clave: i) un tratamiento bastante detallado de la inversión pública y su financiación; ii) la inclusión de siete ámbitos de prestación de servicios públicos, a saber, educación primaria, secundaria y terciaria, salud, agua y saneamiento, infraestructura pública y otros servicios del gobierno; iii) el acceso a servicios del sector privado, tales como educación primaria, secundaria y terciaria, salud y otros servicios privados; iv) la desagregación de otras actividades económicas en diversos sectores, con una contabilidad por separado respecto de cada uno de los sectores que suelen verse más afectados por las conmociones externas (como el café, los textiles y el petróleo); v) la división del trabajo como factor de producción en tres categorías, cada una de las cuales se vincula directamente con un ciclo de enseñanza, a saber, trabajadores que no han finalizado la educación secundaria (no calificados), trabajadores que han finalizado la educación secundaria pero no la terciaria (calificados) y trabajadores que han finalizado la educación terciaria (altamente calificados), y vi) la inclusión del gobierno, un hogar representativo (el sector nacional no gubernamental) y el resto del mundo como agentes institucionales ${ }^{4}$.

\footnotetext{
${ }^{4}$ Entre los otros factores de producción figuran el capital público según la actividad gubernamental, el capital privado y los recursos naturales utilizados en la minería y la agricultura.
} 
Además de la matriz de contabilidad social, el conjunto de datos del modelo mams incluye datos relacionados con los ODM (como se indica en el cuadro 1 respecto de los indicadores no relacionados con la pobreza), el mercado laboral y un conjunto de elasticidades. Otros elementos clave que se utilizaron para calibrar el modelo son: i) un escenario posible según el cual las metas de los oDm se alcanzarían sobre la base de la evolución anterior de los determinantes (véase el cuadro 4); ii) el número de estudiantes que se encuentran en las distintas fases del ciclo de enseñanza; iii) las pautas de comportamiento de los estudiantes en lo que se refiere a índices de promoción y otros indicadores, y iv) el número de trabajadores y las tasas iniciales de desempleo correspondientes a las tres categorías de trabajadores. Todos esos datos provienen de fuentes oficiales: el Banco Central de Nicaragua, el Ministerio de Hacienda y Crédito Público, el Ministerio de Educación y el Instituto Nacional de Información de Desarrollo. Las elasticidades definen el comportamiento de la producción, el comercio, el consumo y las funciones de los ODM. Los modelos logísticos se han estimado desde el punto de vista econométrico para determinar la influencia de los factores relacionados con la oferta y la demanda en los resultados en materia de educación, salud y acceso a agua potable y saneamiento. Las conclusiones de esos análisis empíricos se presentan en Pacheco (2013) y se han utilizado para definir un conjunto de valores de elasticidad a fin de calibrar las funciones de los ODM. Según esos valores, el incentivo salarial parece ser el determinante principal del ingreso y la promoción en la enseñanza primaria de Nicaragua, en tanto que la prestación de servicios per cápita en los rubros de salud, agua y saneamiento (en cuyo caso el gasto público per cápita representa la variable normativa en el modelo MAMS) determina la mayoría de los cambios de las tasas de mortalidad y el acceso al agua potable y al saneamiento básico. Todas las demás elasticidades se han definido sobre la base de estimaciones realizadas para calibrar modelos CGE similares en relación con Nicaragua, que se han utilizado y documentado en Sánchez y Vos (2006 y 2010) y Gámez y otros $(2011)^{5}$.

Después de completar el proceso de calibración del modelo, se generó un escenario base, lo que constituye un punto de referencia con el que se podrían comparar los distintos escenarios alternativos. A partir de un año de base (2006), en el escenario base se reproduce el desempeño económico efectivo en el marco de las políticas

\footnotetext{
5 La base de datos del modelo no se ha incluido como anexo en este documento debido a su tamaño, pero se puede solicitar al autor.
}

aplicadas en años recientes (hasta alrededor de 2012) y se proyectan esas cifras hasta 2020. Entre los supuestos del crecimiento económico figura la desaceleración del crecimiento del PIB ocasionada por la crisis financiera mundial de 2007-2009. El PIB creció a una tasa anual de un 3,1\% durante el período 2007-2012 y se proyecta que siga creciendo en aproximadamente un 4,5\% anual de 2013 a 2020, según el Banco Central de Nicaragua. Con el fin de reproducir fielmente las políticas de gasto público del pasado reciente, el consumo del gobierno y otros componentes del gasto periódico siguen una norma de cierre contable: representan una proporción predefinida del PIB (3,3\% en el caso de la educación; $2,3 \%$ en el de la salud y $0,5 \%$ en el del agua y el saneamiento). El gasto del gobierno en inversiones depende de la demanda de capital en el sector de servicios públicos y dicha demanda, a su vez, varía en función del consumo del gobierno para prestar esos servicios. Con arreglo a otra norma de cierre contable, se supone que todo nuevo déficit (o superávit) fiscal se financia (se ajusta) sobre la base de transferencias (modestas) del resto del mundo, consistentes sobre todo en ayuda en forma de donaciones, se utilizan proyecciones oficiales de los saldos de la deuda externa e interna, con inclusión de los pagos y el alivio de la deuda programados, y se prevé que los ingresos tributarios continúen creciendo lentamente hasta alcanzar el 18,5\% del PIB en 2020. Se presume que la inversión privada se mantiene fija como proporción del PIB, en tanto que las tasas de ahorro de los agentes privados se ajustan en forma endógena, a fin de garantizar que se cumpla el requisito de coherencia del modelo y que el ahorro total sea igual a la inversión total. Mediante la calibración se reproduce también el progreso observado en dirección al logro de los oDM hasta alrededor de 2011, utilizando los valores de elasticidad presentados en el cuadro 4 , y se realizan nuevas proyecciones hacia el futuro en el marco de la continuación antes mencionada de las tendencias y políticas económicas en materia de gastos e ingresos públicos ${ }^{6}$.

El modelo de microsimulaciones se aplicó sobre la base de datos del Estudio de medición de los niveles de vida (LSMS por sus siglas en inglés), realizado por el Instituto Nacional de Información de Desarrollo en 2009. De este modo, se estimaron para cada año del

\footnotetext{
${ }^{6}$ En lo referente a las reglas utilizadas para equilibrar los mercados de factores, se ajustan las rentas para equilibrar el mercado del factor de capital. Los terrenos y los recursos naturales crecen a un ritmo exógeno y son específicos según la actividad de que se trate. El mercado laboral se equilibra mediante el desempleo; siempre que la tasa de desempleo no disminuya hasta una tasa mínima o natural. Alcanzado ese punto, el mercado laboral se equilibra mediante los salarios.
} 
período 2010-2020 los cambios ocupacionales y los cambios de las transferencias con respecto a 2009 , empleando los datos de 2009 del LSMS a fin de realizar las microsimulaciones correspondientes al escenario base y a todos los escenarios hipotéticos alternativos. Las transferencias consisten en transferencias a los hogares ligadas a la educación, cupones de alimentos, subsidios de instituciones y donaciones de amigos o familiares (un indicador indirecto de las remesas, puesto que en su mayoría provienen del extranjero y en el estudio no se identifican específicamente como variable).

El escenario base muestra la evolución de los indicadores de los ODM en el marco de la continuación de las condiciones económicas y las políticas en materia de gastos e ingresos públicos, tomando en consideración las complementariedades o sinergias entre los diversos ODM. Como se describió anteriormente, en el modelo MAMS se tiene en cuenta hasta qué punto la mejora de los niveles de salud contribuye a acelerar el logro del objetivo de la enseñanza, y hasta qué punto un mayor acceso al agua potable y el saneamiento básico ayuda a reducir las tasas de mortalidad. El gasto público continuo en servicios relacionados con los ODM (educación primaria, cuidado de la salud, y agua y saneamiento) es uno de los factores que más aportan a la consecución de los ODM en el escenario base. Principalmente como resultado de ese factor y también de todos los demás determinantes enumerados en el cuadro 4 (con inclusión del consumo per cápita, impulsado por un crecimiento económico constante), se registrarán progresos tendientes al logro de los oDM de acuerdo con el escenario base, pero no todos se podrán alcanzar en 2015 (véase el gráfico 4). Según el escenario base, ni aun en 2020 se alcanzará la meta del índice de finalización del $87 \%$ a la edad prevista para niños y niñas matriculados en la enseñanza primaria. La meta relativa al saneamiento básico se alcanzará en 2019. Hay perspectivas más alentadoras en cuanto al objetivo relacionado con la mortalidad materna, que se podría alcanzar en 2016 gracias a un crecimiento constante del gasto público y privado, así como merced a un mayor acceso a servicios de agua potable y saneamiento. Como se indicará más adelante, la pobreza disminuye en el escenario base, pero no lo suficiente como para alcanzar la meta internacional relacionada con la pobreza extrema.

GRÁFICO 4

Nicaragua: avances hacia el logro de los ODM según el escenario base, 2006-2020 (En porcentajes)

A. ODM 2 y ODM 7s

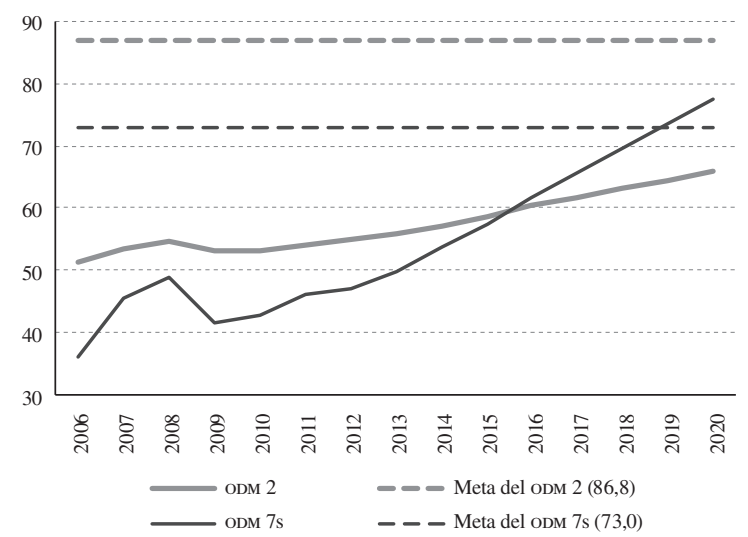

B. ODM 4 y ODM 5

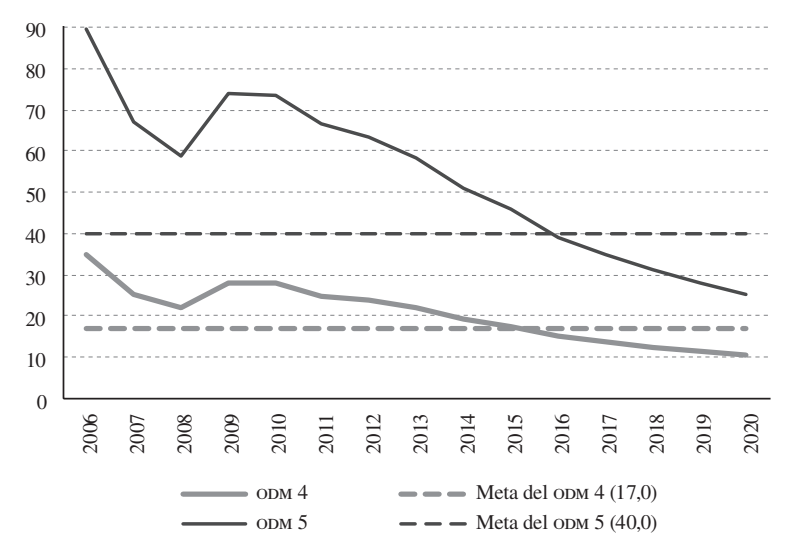

Fuente: elaboración propia sobre la base del Modelo de Simulación sobre los Objetivos de Desarrollo del Milenio (ODM) para Nicaragua.

Nota: los indicadores y metas son coherentes con los presentados en el cuadro 3, con excepción de los del segundo oDM, que en este caso se refieren al índice neto de finalización a tiempo de la enseñanza primaria. La meta del $87 \%$ respecto del indicador del segundo oDM se deriva de la meta del $98 \%$ sobre los índices de matrícula y de finalización en la enseñanza primaria. El oDM $7 \mathrm{~s}$ se refiere a la meta de los oDM sobre el acceso a mejores servicios de saneamiento. 


\section{V}

\section{Análisis de escenarios hipotéticos}

Se analizan dos conjuntos de escenarios hipotéticos mediante la comparación de sus resultados con el escenario base. El primer conjunto abarca cuatro escenarios de financiación en los que se define una vía para la consecución plena de las tres metas no relacionadas con la pobreza que no se alcanzarán en 2015 según el escenario base, como se muestra en el gráfico 4. La variable que se ajusta en estos escenarios es el gasto público, que incluye todas las inversiones y el gasto corriente para prestar servicios de educación primaria pública y, en menor medida, servicios de saneamiento. Este gasto público relacionado con los ODM se incrementa a partir de 2014, hasta que todas las metas no relacionadas con la pobreza que se están examinando se hayan cumplido en 2015 o en 2020 mediante la utilización de recursos extranjeros o ingresos tributarios directos como fuentes alternativas de financiación. El gasto en salud no aumenta porque, al alcanzarse la meta relacionada con el saneamiento y seguirse ampliando el acceso al agua potable en esos escenarios, las tasas de mortalidad se reducen en la medida necesaria para cumplir las metas respectivas. Como se indicó anteriormente, la distancia entre las tasas de mortalidad en 2015 y las metas es pequeña según el escenario base (véase el gráfico 4). En el segundo conjunto de escenarios hipotéticos, el mecanismo de financiación - en cuyo marco se alcanzarían las metas no relacionadas con la pobreza hacia 2020 valiéndose de recursos extranjeros para financiar el gasto público social - se combina con una de las cinco conmociones externas siguientes ${ }^{7}$ :

- pcoffdec: caída del $20 \%$ en el precio mundial del café.

- ptextdec: caída del $20 \%$ en el precio mundial de los textiles.

- poilinc: aumento del $20 \%$ en el precio mundial del petróleo refinado.

- fdidec: reducción de 2 puntos porcentuales del PIB en las entradas de IED.

- remdec: disminución de 2 puntos porcentuales del PIB en las entradas de remesas.

\footnotetext{
${ }^{7}$ Las conclusiones relativas a los efectos de las conmociones externas en el desarrollo humano son casi las mismas si se aplica el supuesto alternativo de que el ingreso tributario sea la fuente de financiación del gasto público. Por consiguiente, no se presentan los resultados correspondientes al escenario de la financiación tributaria en combinación con las conmociones externas, aunque están disponibles previa solicitud.
}

Las cinco conmociones externas se imponen en el período 2014-2020 en referencia al escenario base ${ }^{8}$. Se tomó deliberadamente la decisión de simular conmociones externas relativamente modestas para poder comprender mejor el alto grado de vulnerabilidad externa del desarrollo económico y humano de Nicaragua. Como se mostrará más adelante, las metas no se alcanzarían tan rápido o, en algunos casos, no se llegarían a alcanzar en absoluto en el caso de que conmociones externas como las simuladas acontezcan en la realidad.

\section{Financiación del desarrollo humano y disyuntivas macroeconómicas}

La evidencia según el escenario base indica que el tiempo, dado que ya ha comenzado el año 2015, es insuficiente para que Nicaragua logre los ODM, sobre todo la meta relativa a la finalización de la enseñanza primaria, pero también las referentes al aumento del acceso a servicios básicos de saneamiento y a la reducción de la mortalidad materna (véase el gráfico 4). Las conclusiones correspondientes al primer conjunto de escenarios alternativos sugieren, además, que esos objetivos no se podrán alcanzar en 2015 porque para ello sería necesario concentrar en las fases iniciales un considerable gasto público adicional, que tendría que mantenerse después de 2015 a fin de evitar retrocesos en el desarrollo humano ${ }^{9}$. El gasto público en enseñanza primaria tendría que incrementarse en aproximadamente 6 puntos porcentuales del PIB (casi el $67 \%$ del PIB se asignaría al consumo del gobierno) para que el índice de finalización de la enseñanza primaria se acercara a la meta establecida con respecto al año 2015 (véase el cuadro 5). Otro punto porcentual del PIB, o un poco más, sería necesario para mejorar los servicios básicos de saneamiento, sobre todo mediante la inversión en infraestructura de saneamiento, con miras a alcanzar la meta pertinente y, a su vez, allanar el camino para el logro del objetivo relacionado con la mortalidad materna en 2015. El gasto público adicional necesario

\footnotetext{
8 Téngase en cuenta que todos los escenarios alternativos se generan a partir de 2006, pero solo se desvían de la línea de base a partir de 2014 .

${ }^{9}$ De hecho, en el escenario en que se alcanzan las metas no relacionadas con la pobreza en 2015 , la proporción del gasto público vinculado a los ODM en porcentaje del PIB en ese año se mantiene constante en el período 2016-2020, de modo que los indicadores de los ODM siguen mejorando como resultado de un crecimiento constante del PIB.
} 
Nicaragua: gasto público necesario para alcanzar las metas según escenarios hipotéticos de financiación de los ODM, 2006-2020

(En porcentajes del PIB)

\begin{tabular}{|c|c|c|c|c|c|c|}
\hline & \multicolumn{2}{|c|}{ Gasto en el escenario base } & \multicolumn{4}{|c|}{$\begin{array}{l}\text { Gasto anual adicional necesario en } 2014-2020 \text { según los escenarios } \\
\text { de financiación con que se procura alcanzar las metas en: }\end{array}$} \\
\hline & 2006-2013 & 2014-2020 & $\begin{array}{c}2015, \text { con } \\
\text { endeudamiento } \\
\text { externo }\end{array}$ & $\begin{array}{l}\text { 2015, con } \\
\text { tributación } \\
\text { directa }\end{array}$ & $\begin{array}{c}\text { 2020, con } \\
\text { endeudamiento } \\
\text { externo }\end{array}$ & $\begin{array}{l}\text { 2020, con } \\
\text { tributación } \\
\text { directa }\end{array}$ \\
\hline Educación & 1,63 & 1,67 & 6,04 & 6,10 & 3,71 & 4,29 \\
\hline Consumo & 1,49 & 1,47 & 4,05 & 4,05 & 2,56 & 2,92 \\
\hline Inversión & 0,14 & 0,20 & 1,99 & 2,05 & 1,14 & 1,36 \\
\hline Salud & 2,33 & 2,50 & 0,00 & 0,00 & 0,00 & 0,00 \\
\hline Consumo & 2,08 & 2,17 & 0,00 & 0,00 & 0,00 & 0,00 \\
\hline Inversión & 0,25 & 0,33 & 0,00 & 0,00 & 0,00 & 0,00 \\
\hline Agua y saneamiento & 0,51 & 0,66 & 1,22 & 1,14 & 0,00 & 0,00 \\
\hline Consumo & 0,01 & 0,01 & 0,34 & 0,34 & 0,00 & 0,00 \\
\hline Inversión & 0,51 & 0,65 & 0,88 & 0,80 & 0,00 & 0,00 \\
\hline Total & 4,48 & 4,83 & 7,26 & 7,24 & 3,71 & 4,29 \\
\hline
\end{tabular}

Fuente: elaboración propia sobre la base del Modelo de Simulación sobre los Objetivos de Desarrollo del Milenio (oDM) para Nicaragua. PIB: producto interno bruto.

para alcanzar de una vez todas las metas no relacionadas con la pobreza representa un poco más del $7 \%$ del PIB, lo que supera con creces el gasto relacionado con los ODM del 4,8\% del PIB, registrado en la línea de base ${ }^{10}$.

La financiación de tan grandes volúmenes de gasto público no sería realista en el tiempo dado el plazo establecido (2015). La deuda pública externa aumentaría en 23 puntos porcentuales del PIB en 2015 y en 44 puntos porcentuales del PIB en 2020, respectivamente, en relación con la línea de base, según el escenario hipotético en que el gasto público adicional relacionado con los oDM se financia íntegramente con el endeudamiento externo y no con la ayuda (véase el gráfico 5.A) ${ }^{11}$. La alternativa que se analiza en este caso consiste en financiar el gasto público adicional necesario para lograr los objetivos no relacionados con la pobreza mediante el engrosamiento de la recaudación de ingresos tributarios directos en

\footnotetext{
10 Sánchez y Vos (2009 y 2010) estimaron que el gasto público adicional necesario para alcanzar las metas de los ODM no relacionadas con la pobreza en Nicaragua en 2015 equivalía al 6,4\% del PIB. La cifra utilizada en el presente documento es algo mayor, porque el período de simulación hasta 2015 es más breve (en otras palabras, el año de base es más cercano) y el escenario base tiene en cuenta con mayor precisión los efectos desfavorables de la crisis financiera mundial en los ODM debido a la utilización de datos más recientes.

11 La financiación externa es necesaria más allá de 2015 para conseguir que la proporción del gasto público relacionado con los ODM en porcentaje del PIB en 2015 se mantenga constante en el lapso 2016-2020. En el caso del escenario base, la deuda pública externa desciende bruscamente de acuerdo con la tendencia observada en años anteriores y con las proyecciones oficiales de los saldos de la deuda externa en que se tienen en cuenta los pagos y el alivio de la deuda programados.
}

12 puntos porcentuales del PIB en 2015 y en 5 puntos porcentuales del PIB en 2020, respectivamente, con respecto a la línea de base (véase el gráfico 5.B). Esa estrategia de financiación tampoco sería factible si se tiene en cuenta que el gobierno ya ha realizado esfuerzos concertados para subir los impuestos.

Para los encargados de la formulación de políticas en Nicaragua sería más realista aplicar una estrategia de los ODM con un plazo relativamente más amplio, en cuyo caso la concentración del gasto y la financiación públicos en las fases iniciales no tendría que ser tan elevada ni pondría en peligro la orientación fiscal. Los escenarios alternativos al escenario base indican que el gobierno ahorraría 3 puntos porcentuales del PIB o más del gasto público si se propusiera cumplir los oDM no relacionados con la pobreza en 2020 en lugar de 2015 (véase el cuadro 5). El gasto público adicional necesario con miras a garantizar la consecución del objetivo de la finalización del nivel primario hacia 2020 estimularía posteriormente el crecimiento económico al existir un menor grado de austeridad fiscal, lo que a su vez fomentaría el empleo y ayudaría a reducir la incidencia de la pobreza. El consiguiente aumento del ingreso per cápita incentivaría la demanda privada de educación, cuidado de salud y agua y saneamiento, provocando un efecto positivo en los avances hacia el logro de los oDM. Según el escenario del endeudamiento externo, el acceso al saneamiento básico se podría lograr hacia 2020, en tanto que las metas relativas a la mortalidad de los niños menores de cinco años y la mortalidad materna se alcanzarían en 2015 y 2016, respectivamente. 
GRÁFICO 5

\section{Nicaragua: deuda pública externa e ingresos tributarios según el escenario base y de financiación de los ODM, 2006, 2015 y 2020 \\ (En porcentajes del PIB)}

A. Deuda pública externa

según el escenario del endeudamiento externo

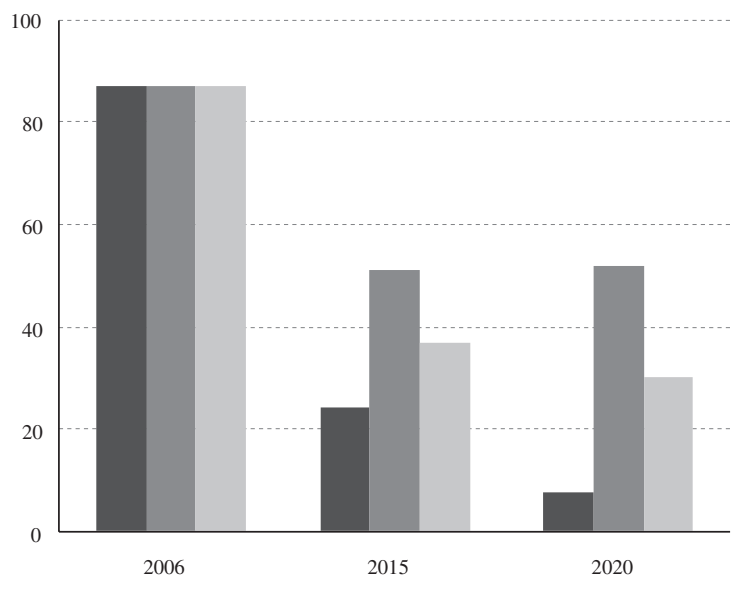

Línea de base
B. Ingresos tributarios según el escenario de la financiación tributaria

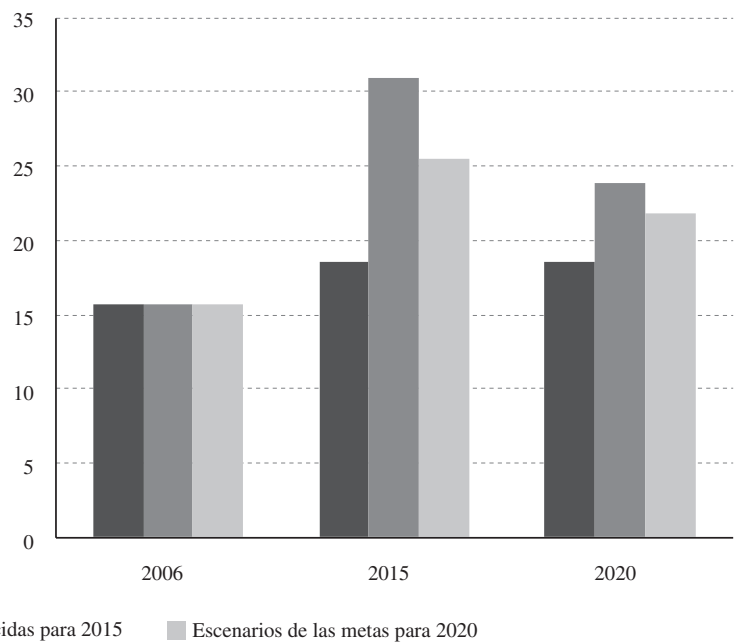

Fuente: elaboración propia sobre la base del Modelo de Simulación sobre los Objetivos de Desarrollo del Milenio (oDM) para Nicaragua. PIB: producto interno bruto.

El gasto público adicional necesario para alcanzar todas las metas no relacionadas con la pobreza en 2020 es de 0,6 puntos porcentuales del PIB menos si la fuente de financiación proviene del endeudamiento externo en lugar de los impuestos (véase el cuadro 5). La tributación directa redunda en que se reduzca el ingreso disponible privado y, por lo tanto, deprime la demanda privada de servicios sociales, como la educación, y limita el ahorro privado disponible para la inversión (véase el cuadro 6). De acuerdo con el escenario de la tributación directa, el gobierno tendría que aumentar en mayor medida el gasto (en comparación con el escenario de la financiación externa) para poder contrarrestar la disminución del gasto privado y alcanzar las metas. El nuevo gasto público inyectado en los sectores no comercializables de la economía impondría presión sobre el tipo de cambio real, lo que contribuiría a una apreciación que debilitaría el crecimiento de las exportaciones y estimularía el de las importaciones en comparación con el escenario base. El efecto de la apreciación del tipo de cambio real se vería exacerbado si se movilizaran las entradas de recursos extranjeros para financiar las necesidades adicionales en materia de gasto público. Además, según el escenario del endeudamiento externo, se necesitaría relativamente menos financiación para costear el gasto público adicional si las metas se alcanzaran en 2020: la deuda pública externa representaría el 30\% del PIB en 2020 si las metas se alcanzaran en ese año, 20 puntos porcentuales menos en comparación con el escenario correspondiente, según el cual las metas se alcanzarían en 2015 (véase el gráfico 5).

La estrategia de financiación que se aplique repercutirá en el crecimiento del PIB. En los escenarios de financiación externa, el incremento del PIB era ligeramente mayor en comparación con el escenario base, en tanto que la utilización de la tributación directa en los escenarios alternativos de financiación afectaría al crecimiento económico, pues desplazaría el gasto privado en comparación con todos los demás escenarios (véase el cuadro 6) ${ }^{12}$. Del corto al mediano plazo, Nicaragua puede seguir recurriendo a fuentes externas para complementar los recursos internos destinados a la financiación del gasto con vistas al logro de los objetivos de desarrollo humano. No obstante, la reducción de la dependencia de la ayuda y de los préstamos en condiciones favorables impondrá

\footnotetext{
${ }^{12}$ Se espera que el crecimiento del PIB y sus componentes de gasto sean levemente mayores cuando se moviliza la financiación para lograr los oDM en 2015, porque el estímulo derivado de concentrar en las fases iniciales el gasto público relacionado con dichos objetivos es mucho mayor. Esto no es válido en el caso del escenario de la financiación tributaria debido al efecto de desplazamiento en el gasto privado.
} 


\begin{tabular}{|c|c|c|c|c|c|c|}
\hline & \multirow{2}{*}{$\begin{array}{l}2007-2013 \\
\text { en todos los } \\
\text { escenarios }\end{array}$} & \multirow{2}{*}{$\begin{array}{c}\text { 2014-2020 } \\
\text { en el escenario } \\
\text { base }\end{array}$} & \multicolumn{4}{|c|}{$\begin{array}{l}\text { 2014-2020, según los escenarios de financiación } \\
\text { que procuran alcanzar las metas en: }\end{array}$} \\
\hline & & & $\begin{array}{c}2015, \text { con } \\
\text { endeudamiento } \\
\text { externo }\end{array}$ & $\begin{array}{l}\text { 2015, con } \\
\text { tributación } \\
\text { directa }\end{array}$ & $\begin{array}{c}\text { 2020, con } \\
\text { endeudamiento } \\
\text { externo }\end{array}$ & $\begin{array}{c}2020, \text { con } \\
\text { tributación } \\
\text { directa }\end{array}$ \\
\hline Consumo privado & 2,13 & 3,58 & 4,15 & 3,21 & 3,89 & 3,22 \\
\hline Consumo del gobierno & 0,89 & 4,48 & 8,71 & 8,78 & 6,97 & 7,34 \\
\hline Inversión privada & 6,17 & 3,88 & 3,99 & 3,49 & 3,93 & 3,59 \\
\hline Inversión del gobierno & 4,37 & 7,77 & 57,50 & 48,97 & 22,18 & 22,92 \\
\hline Exportaciones & 6,36 & 5,46 & 5,15 & 4,74 & 4,68 & 4,95 \\
\hline Importaciones & 2,73 & 4,06 & 4,64 & 3,62 & 4,26 & 3,75 \\
\hline PIB & 3,24 & 4,42 & 4,59 & 4,34 & 4,51 & 4,37 \\
\hline
\end{tabular}

Fuente: elaboración propia sobre la base del Modelo de Simulación sobre los Objetivos de Desarrollo del Milenio (ODM) para Nicaragua. PIB: producto interno bruto.

la necesidad de mayores reformas fiscales para que la financiación externa se pueda sustituir gradualmente por los ingresos tributarios. Además, la utilización de recursos extranjeros para financiar el desarrollo durante un largo período podría socavar la competitividad de las exportaciones debido a la apreciación del tipo de cambio real. A su vez, esto podría desalentar las exportaciones, lo que entrañaría un aumento del déficit externo y daría lugar a un cambio estructural no deseado consistente en el distanciamiento de las industrias más dinámicas, con el consiguiente obstáculo para el crecimiento económico.

Esas estrategias de financiación simuladas de los ODM también tendrían consecuencias desde el punto de vista de la pobreza y la desigualdad. La incidencia de la pobreza y de la pobreza extrema a nivel nacional se reduce en forma drástica de acuerdo con el escenario base en 8,7 puntos porcentuales y 4,2 puntos porcentuales, respectivamente, entre 2009 y 2020 (véase el cuadro 7). De esas reducciones, 7,3 puntos porcentuales y 4 puntos porcentuales, respectivamente, se pueden atribuir a un aumento general del bienestar de la población gracias al mejoramiento de las rentas del trabajo, y el resto del cambio se basa en las transferencias del gobierno y del resto del mundo.

Cuando el gasto público adicional se incrementa y se costea mediante recursos provenientes del exterior a fin de alcanzar las metas de los ODM no relacionadas con la pobreza hacia 2020, el impulso de la demanda tiene un efecto multiplicador en toda la economía, con lo que aumentan los salarios medios y se reduce el desempleo. Esos efectos en el mercado laboral producen mejoras de los ingresos netos que dan pie a nuevas reducciones de las tasas de pobreza moderada y extrema, con lo que se alcanza el objetivo internacional de aminorar la pobreza extrema al 9,7\% (véase el cuadro 7). Sin embargo, ese resultado no se reproduce con el escenario de la financiación tributaria, en la que las tasas de pobreza son en realidad más elevadas que en el escenario base como resultado del efecto de desplazamiento en el gasto privado, que sirve para contrarrestar el impulso de la demanda

\begin{abstract}
Nicaragua: indicadores de pobreza y coeficiente de Gini según el escenario base y de financiación de los ODM, utilizando el año 2020 como plazo para alcanzar las metas, 2009, 2015 y 2020
\end{abstract}

\begin{tabular}{|c|c|c|c|c|c|c|c|}
\hline & \multirow{2}{*}{2009} & \multicolumn{2}{|c|}{ Escenario base } & \multicolumn{2}{|c|}{ Financiación externa } & \multicolumn{2}{|c|}{$\begin{array}{c}\text { Ingresos tributarios } \\
\text { directos }\end{array}$} \\
\hline & & 2015 & 2020 & 2015 & 2020 & 2015 & 2020 \\
\hline Pobreza moderada nacional (en porcentajes) & 42,5 & 39,5 & 33,8 & 33,4 & 27,6 & 39,8 & 34,1 \\
\hline Pobreza extrema nacional (en porcentajes) & 14,6 & 12,9 & 10,4 & 12,0 & 9,5 & 13,5 & 10,7 \\
\hline Coeficiente de Gini del consumo per cápita & 0,4828 & 0,4798 & 0,4832 & 0,4876 & 0,4924 & 0,4802 & 0,4836 \\
\hline
\end{tabular}

Fuente: elaboración propia sobre la base del Modelo de Simulación sobre los Objetivos de Desarrollo del Milenio (oDM) para Nicaragua. 
derivado del gasto público. Las tasas de pobreza no se reducen en mayor medida en los escenarios de financiación porque —además de los efectos macroeconómicos desfavorables antes mencionados de la financiación del gasto público (desplazamiento del gasto privado y menor competitividad de las exportaciones) - los salarios se distribuyen menos equitativamente a medida que aumenta la demanda del sector público de médicos, maestros y otros trabajadores altamente calificados, que no abundan en Nicaragua. El coeficiente de Gini del consumo per cápita es mayor en todos los escenarios de financiación de los ODM que en el escenario base.

\section{Vulnerabilidad externa del desarrollo humano}

Las perspectivas económicas de Nicaragua están a punto de mejorar si el nuevo estímulo del gasto público simulado a fin de alcanzar los objetivos de desarrollo no se ve contrarrestado por las disyuntivas macroeconómicas de la financiación del desarrollo. No obstante, también se deben tener en cuenta las vulnerabilidades externas. Nicaragua ha experimentado reducciones de los precios de exportaciones clave, aumentos del precio del petróleo que han acarreado un costo mucho mayor de importación del crudo, y descensos desfavorables en las entradas de IED y remesas. Esas conmociones externas ponen en peligro la estabilidad de la balanza de pagos y socavan el crecimiento económico, lo que puede dar pie a retrocesos en el desarrollo humano. Las conmociones externas simuladas como parte del escenario de la financiación externa —utilizando el año 2020 como plazo para alcanzar las metas- eran de una magnitud relativamente modesta, pero tenían el potencial de debilitar el crecimiento del PIB (véase el gráfico 6). Por ejemplo, una reducción de dos puntos porcentuales del PIB en las entradas de IED hace que la inversión privada y las exportaciones se contraigan hasta un punto en que el crecimiento del PIB disminuye en casi un cuarto de punto porcentual. Los pequeños retrocesos de los precios mundiales de los principales productos básicos de exportación, como el café, también han repercutido negativamente en el crecimiento económico.

Independientemente de los distintos mecanismos de transmisión mediante los cuales las conmociones externas simuladas dañarían la economía, dichas conmociones —incluso las de modesta magnitud — podrían limitar el crecimiento económico en Nicaragua. Ellas tendrían un efecto en los determinantes clave del logro de los ODM, como la prestación de servicios (utilizando como indicador indirecto del gasto público y privado en sectores sociales) y el consumo per cápita de los hogares. En términos proporcionales, el gasto público social en porcentaje del PIB es el mismo en los escenarios de financiación con y sin conmociones externas. Sin embargo, la retracción

GRÁFICO 6

Nicaragua: crecimiento del PIB real según el escenario de la financiación externa utilizando el año 2020 como plazo para alcanzar las metas, con y sin conmociones externas, 2014-2020

(En porcentajes del PIB)

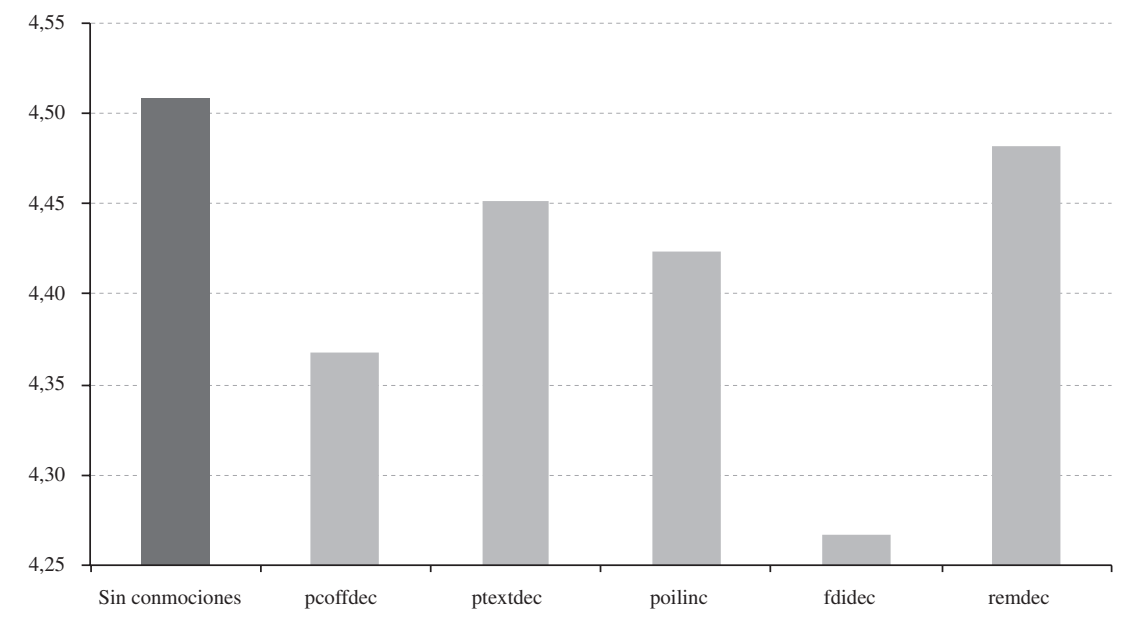

Fuente: elaboración propia sobre la base del Modelo de Simulación sobre los Objetivos de Desarrollo del Milenio (ODM) para Nicaragua.

a pcoffdec: caída del $20 \%$ en el precio mundial del café; ptextdec: caída del $20 \%$ en el precio mundial de los textiles; poilinc: aumento del $20 \%$ en el precio mundial del petróleo refinado; fdidec: reducción de 2 puntos porcentuales del producto interno bruto (PIB) en las entradas de inversión extranjera directa (IED); remdec: reducción de 2 puntos porcentuales del PIB en las entradas de remesas. 
del crecimiento del PIB derivada de las conmociones externas simuladas implica, en términos absolutos, un menor gasto público social que en el escenario sin conmociones externas. Estas también repercuten en los indicadores de los oDM debido a la reducción del gasto privado en servicios sociales y del consumo per cápita. Como consecuencia, el avance hacia el logro de los ODM resulta menos alentador sea cual sea el rasero que se le aplique. En el escenario de financiación con cualquiera de las conmociones externas, no se alcanzaría la meta relacionada con el índice neto de finalización de la enseñanza primaria (véase el gráfico 7). Además, la reducción del consumo per cápita va a la par de la caída de las rentas del trabajo por unidad familiar, debido a la desaceleración del crecimiento económico provocada por las conmociones externas. Por consiguiente, la pobreza extrema también se abultaría, sobre todo cuando el escenario de financiación se combina con la conmoción del precio del petróleo. Aunque no se indica en el gráfico 7 para no hacerlo más complejo, la meta internacional relativa a la pobreza extrema ya no se alcanza con ninguna de las conmociones, y el logro de las metas en materia de mortalidad materna y saneamiento se retrasa cuando se simulan las conmociones relacionadas con el precio del petróleo y las remesas como parte del escenario de financiación. En consecuencia, las conmociones externas relativamente modestas tienen el potencial de incrementar el gasto público necesario para cumplir los ODM, lo que se traduce en que el desarrollo humano sea una aspiración más difícil para Nicaragua.

GRÁFICO 7
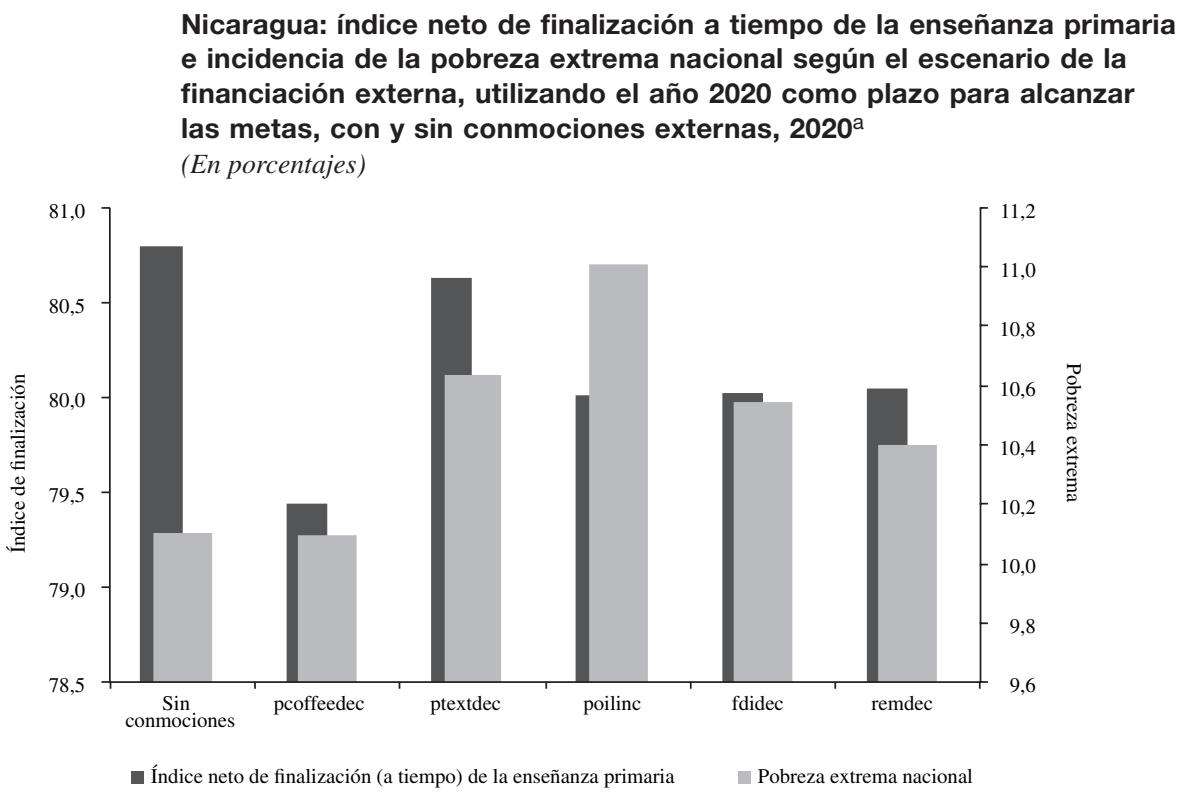

Fuente: elaboración propia sobre la base del Modelo de Simulación sobre los oDM para Nicaragua y el modelo de microsimulaciones correspondiente a Nicaragua.

a pcoffdec: caída del $20 \%$ en el precio mundial del café; ptextdec: caída del $20 \%$ en el precio mundial de los textiles; poilinc: aumento del $20 \%$ en el precio mundial del petróleo refinado; fdidec: reducción de 2 puntos porcentuales del producto interno bruto (PIB) en las entradas de inversión extranjera directa (IED); remdec: reducción de 2 puntos porcentuales del PIB en las entradas de remesas. 


\section{VI}

\section{Conclusiones y consecuencias en materia de políticas}

Nicaragua es una economía en desarrollo pequeña y abierta, que ha registrado notables progresos económicos y sociales en los dos últimos decenios, pero aún presenta tasas elevadas de pobreza extrema y desigualdad de los ingresos. Su crecimiento económico suele fluctuar en respuesta a factores externos. La economía afronta limitaciones tenaces y apremiantes en lo que respecta a la generación de recursos internos y debido al intercambio con el resto del mundo. Depende en alto grado de la financiación externa, incluidos los préstamos, la ayuda en forma de donaciones y el alivio de la deuda. Dadas esas limitaciones para la movilización de recursos, Nicaragua tropieza con dificultades para el logro de los objetivos de desarrollo.

En sentido general, el avance en pos del logro de los ODM ha sido satisfactorio. Se han reducido las tasas de pobreza extrema y de mortalidad infantil y materna, y una proporción cada vez mayor de la población tiene acceso al agua potable. Sin embargo, dicho avance no ha sido igual de alentador en lo concerniente al logro de mayores índices de finalización de la enseñanza primaria y de un mayor acceso a servicios básicos de saneamiento. El análisis de los escenarios expuestos en este documento corrobora las conclusiones presentadas en Sánchez y Vos (2009 y 2010). Es decir, se espera que la continuación de las tendencias y políticas económicas existentes en materia de gasto e ingreso públicos se traduzca en avances hacia el logro de los ODM, con inclusión de una marcada tendencia a la reducción de la pobreza, pero no al nivel necesario para que el país alcance todas las metas en 2015. En el presente documento se amplía el período de simulación hasta 2020, a fin de evaluar escenarios más realistas.

Nicaragua necesitaría un aumento del gasto público social de alrededor del 7\% del PIB cada año a fin de subsanar las deficiencias de los ODM en 2015 y mantener encaminados todos los indicadores a partir de entonces, en relación con el escenario base de crecimiento constante del PIB y mantenimiento de las políticas de gasto público. Aproximadamente el $87 \%$ de ese nuevo gasto tendría que asignarse a la enseñanza primaria. Las repercusiones macroeconómicas de la financiación de semejante volumen de gasto adicional son considerables. El crecimiento económico se vería socavado si el gobierno optara por utilizar altos niveles de ingresos tributarios adicionales, pues ello frenaría el gasto privado y la demanda de servicios sociales privados. Como alternativa, las entradas de recursos extranjeros no desplazarían al gasto privado sino que, en forma de préstamos, detendrían la disminución de la deuda externa y erosionarían la competitividad de las exportaciones debido a la apreciación del tipo de cambio real. Se evidenciaría la misma disyuntiva si dichos recursos externos se recibieran en forma de donaciones (aunque sin acumulación de la deuda). En vista de esas conclusiones, Nicaragua no está en condiciones de lograr los ODM en 2015.

Con la llegada de 2015, el gobierno no cuenta con el plazo necesario para emprender medidas de política en pos de cumplir todos los oDM a tiempo. Sería más factible si el país retrasara el logro de aquellos objetivos más difíciles. Esto no solo propiciaría en mayor medida la obtención de la financiación necesaria, sino que también contribuiría a que los efectos del aumento del gasto público se multiplicaran más ampliamente en toda la economía. Con ello se aceleraría el crecimiento económico y esto, a su vez, ayudaría al gobierno a ganar tiempo para reducir la dependencia de recursos extranjeros y cosechar los beneficios de las reformas fiscales recientes. Los escenarios desarrollados en relación con las políticas que se requerirían demuestran que el hecho de retrasar hasta 2020 el logro de los ODM se traduciría en que el gasto público social adicional necesario se redujera al $3,7 \%$ o al $4,3 \%$ del PIB, dependiendo, respectivamente, de si la fuente de la financiación es externa o de tributación directa. Esos escenarios plantean una situación de financiación pública mucho más realista: por ejemplo, al emplear el endeudamiento externo, el saldo de la deuda externa aumentaría en 20 puntos porcentuales menos del PIB si se plantea el logro de los ODM para 2020 que si se hubiera planteado para 2015. En ese caso, la trayectoria de la deuda externa seguiría siendo sostenible y más cercana al saldo relativamente bajo y descendente del escenario base. El efecto multiplicador ocasionado por la mayor gradualidad del gasto del gobierno en los sectores sociales a lo largo de un período más extenso 
aportaría 1,3 puntos porcentuales más de crecimiento anual del PIB en relación con la línea de base. Dichos aumentos no reflejan los beneficios a muy largo plazo para el crecimiento económico que podrían esperarse al invertir en el logro de los oDM. Esos beneficios se derivarían de la acumulación de los factores y el crecimiento de la productividad al emplear a lo largo de los años un mayor número de trabajadores más instruidos y con mejor salud, como Sánchez y Cicowiez (2014) demostraron recientemente en el caso de cuatro países en desarrollo. Por lo tanto, es realista pensar que, más allá de 2020, Nicaragua podría esperar beneficios económicos de sus inversiones anteriores en materia de desarrollo humano.

Los encargados de la formulación de políticas en Nicaragua no podrán evitar recurrir al endeudamiento externo si desean financiar las inversiones necesarias para lograr los ODM. La ayuda en forma de donaciones extranjeras ya no es una opción viable (a menos que los donantes reviertan sistemáticamente su declive) y el país necesita tiempo para cosechar los beneficios de las reformas fiscales recientes. No obstante, las fuentes extranjeras de financiación deberán sustituirse gradualmente por nuevos ingresos tributarios, a objeto de que el gobierno pueda cumplir su compromiso de reducir los niveles de la deuda externa.

En todas las intervenciones encaminadas a lograr una mayor movilización de recursos se tendrán que contemplar las necesidades de gasto público, no solo para lograr los objetivos en materia de desarrollo humano, sino para mantener al país enfocado a su cumplimiento en vista de los turbulentos episodios económicos ocasionados por las conmociones externas. El análisis de los escenarios expuesto en este documento resalta que el desarrollo humano en Nicaragua es altamente vulnerable ante conmociones externas modestas, ya sean causadas por precios mundiales desfavorables o por una reducción de las entradas de IED o de las remesas. Como se indica en el análisis, esas conmociones podrían frenar el estímulo económico del gasto público y arrastrar consigo al ingreso per cápita, lo que provocaría ciertos retrocesos en las esferas del desarrollo humano y la pobreza, hasta el punto de que muchas de las metas ya no serían alcanzables ni siquiera hacia 2020.

La reducción de la pobreza y la exposición a las vulnerabilidades externas requerirán políticas activas que estimulen el crecimiento sostenido de la economía y el empleo por medio de la diversificación de la producción y las exportaciones. Además, el crecimiento económico debería ser más incluyente, para lo cual convendría asegurarse de integrar en la transformación productiva nuevas tecnologías y actividades que exigen una mano de obra calificada, mejorar el contenido de la enseñanza y hacer que los conocimientos especializados impartidos a través del sistema educativo sean objeto de una elevada demanda del sector de la producción. Dichos cambios podrían ser puestos en marcha por los planes nacionales de desarrollo vigentes, cuyo objetivo es atraer la IED y dar comienzo a proyectos de inversión de gran envergadura en infraestructura pública. En un sentido más amplio, esas conclusiones y lecciones de política se aplican a la mayoría de las economías en desarrollo pequeñas y abiertas que tratan de lograr los objetivos de desarrollo humano, y podrían ser una valiosa contribución para la formulación de la agenda de las Naciones Unidas con respecto al desarrollo sostenible después de 2015.

\section{Bibliografía}

CEPAL (Comisión Económica para América Latina y el Caribe) (2013), Panorama Social de América Latina 2012 (LC/ G.2557-P), Santiago de Chile. Publicación de las Naciones Unidas, $\mathrm{N}^{\circ}$ de venta: S.13.II.G.6.

Gámez, O. y otros (2011), "Nicaragua", Vulnerabilidad económica externa, protección social y pobreza en América Latina, M.V. Sánchez y P. Sauma (eds.), Quito, Facultad Latinoamericana de Ciencias Sociales (FLACSO)/Comisión Económica para América Latina y el Caribe (CEPAL)/Departamento de Asuntos Económicos y Sociales de las Naciones Unidas.

Guimarães, J. y N. Avendaño (2011), "The great experiment: testing the PRSP approach in Nicaragua, 2000-2007", European Journal of Development Research, vol. 23, $\mathrm{N}^{\circ} 2$, Palgrave Macmillan.

Lofgren, H. y C. Díaz-Bonilla (2010), "Mams: an economy-wide model for analysis of MDG country strategies - an application to Latin America and the Caribbean", Public Policies for Human Development. Feasible Financing Strategies for Achieving MDGs in Latin America and the Caribbean, M.V. Sánchez y otros (eds.), Londres, Palgrave Macmillan.
Lofgren, H., M. Cicowiez y C. Díaz-Bonilla (2013), "MAms-A computable general equilibrium model for developing country strategy analysis", Handbook of Computable General Equilibrium Modelling, P.B. Dixon y D.W. Jorgenson (eds.), vol. 1A, Amsterdam, North-Holland.

Pacheco, J. (2013), "Determinantes socioeconómicos de la educación, la mortalidad y el acceso al agua potable y el saneamiento en Nicaragua: Un análisis econométrico" [en línea] http:// www.un.org/en/development/desa/policy/capacity/country_ documents/nicaragua_determinantes.pdf.

Sánchez, M.V. (2011), "Welfare effects of rising oil prices in oilimporting developing countries", The Developing Economies, vol. 49, $\mathrm{N}^{\circ} 3$, Instituto de las Economías en Desarrollo.

Sánchez, M.V. y M. Cicowiez (2014), "Trade-offs and payoffs of investing in human development", World Development, vol. 62, Amsterdam, Elsevier.

Sánchez, M.V. y R. Vos (2010), "Nicaragua", Public Policies for Human Development. Feasible Financing Strategies for Achieving MDGs in Latin America and the Caribbean, M.V. Sánchez y otros (eds.), Londres, Palgrave Macmillan. 
(2009), "Impact of the global crisis on the achievement of the MDGs in Latin America", DESA Working Paper, $\mathrm{N}^{\circ} 74$, Nueva York, Departamento de Asuntos Económicos y Sociales [en línea] http://www.un.org/esa/desa/papers/2009/wp74_2009. pdf.

(2006), "DR-CAFTA: ¿Panacea o fatalidad para el desarrollo económico y social en Nicaragua?", serie Estudios y
Perspectivas, $\mathrm{N}^{\circ} 57$ (LC/MEX/L.752), México, D.F., Sede Subregional de la CEPAL en México [en línea] http://www. eclac.cl/publicaciones/xml/0/27210/L752.pdf.

Vos, R. y M.V. Sánchez (2010), "A non-parametric microsimulation approach to assess Changes in inequality and poverty", International Journal of Microsimulation, vol. $3, \mathrm{~N}^{\circ} 1$ [en línea] http://microsimulation.org/IJM/V3_1/IJM_25.pdf. 